\title{
Circadian regulation of metabolism
}

\author{
Shannon M Bailey', Uduak S Udoh ${ }^{1}$ and Martin E Young ${ }^{2}$ \\ ${ }^{1}$ Division of Molecular and Cellular Pathology, Department of Pathology and ${ }^{2}$ Division of Cardiovascular Diseases, \\ Department of Medicine, University of Alabama at Birmingham, 703 19th Street South, ZRB 308, Birmingham, \\ Alabama 35294, USA
}

\author{
Correspondence \\ should be addressed \\ to $M$ E Young \\ Email \\ meyoung@uab.edu
}

\begin{abstract}
In association with sleep-wake and fasting-feeding cycles, organisms experience dramatic oscillations in energetic demands and nutrient supply. It is therefore not surprising that various metabolic parameters, ranging from the activity status of molecular energy sensors to circulating nutrient levels, oscillate in time-of-day-dependent manners. It has become increasingly clear that rhythms in metabolic processes are not simply in response to daily environmental/behavioral influences, but are driven in part by cell autonomous circadian clocks. By synchronizing the cell with its environment, clocks modulate a host of metabolic processes in a temporally appropriate manner. The purpose of this article is to review current understanding of the interplay between circadian clocks and metabolism, in addition to the pathophysiologic consequences of disruption of this molecular mechanism, in terms of cardiometabolic disease development.
\end{abstract}

\section{Key Words}

- circadian rhythms

- glucose metabolism

- lipid

- metabolism
Journal of Endocrinology (2014) 222, R75-R96

\section{Introduction}

Both energetic supply and demand fluctuate as a function of time-of-day, concomitant with daily sleep-wake and fasting-feeding cycles. It is therefore not surprising that marked diurnal variations in metabolism are observed at multiple levels. Metabolic parameters ranging from circulating nutrient levels and substrate utilization to energy expenditure and thermogenesis have been reported to fluctuate over the course of the day. For example, body temperature and energy expenditure are both elevated in the laboratory rodent during the awake period, in association with behaviors known to elicit a positive thermic effect (e.g. increased physical activity and food intake; Alberts et al. 2006, Yang et al. 2010, Bray et al. 2013). In contrast to the laboratory rodent or the typical human in the civilized world, rhythms in distinct metabolic parameters are presumably less predictable for the animal in the wild; physical activity is anticipated to be elevated during the awake (vs sleep) phase in association with behaviors such as foraging for food, avoidance of predation, and reproduction, while food availability is somewhat less predictable on a daily basis. The organism must therefore 'hedge its bets', by maintaining metabolic flexibility, such that homeostasis can be achieved whether or not foraging is successful during the active period. Undoubtedly, endocrine factors play critical roles in this process, signaling transition of both activity and feeding status. However, what is becoming increasingly clear is that behavior-independent endogenous mechanisms also contribute toward daily rhythms in metabolism; one such mechanism is the cell autonomous circadian clock, which allows the cell to anticipate a predictable daily stimulus before its onset. In this review, we will discuss current knowledge regarding the regulation of time-of-day-dependent oscillations in metabolism, with a specific focus on the interplay between extracellular (e.g. endocrine) and intracellular (e.g. circadian clock) factors.

\section{Extrinsic vs intrinsic regulation}

It has become increasingly clear that $24 \mathrm{~h}$ rhythms in multiple biological processes, including metabolism, are

Published by Bioscientifica Ltd 
mediated not only by environmental (i.e. extrinsic) factors but also by endogenous (i.e. intrinsic) influences. Dissociation of these two influences is possible when environmental conditions are maintained constant over the course of the day (i.e. constant lighting and food availability in the absence of synchronizing environmental cues); under such conditions, behavioral (sleep-wake and feeding-fasting), endocrine, and metabolic cycles persist in both humans and rodent models (with periodicities slightly longer and shorter than $24 \mathrm{~h}$ respectively) (Aschoff 1965, Pittendrigh \& Daan 1976). Time-of-day-dependent oscillations in both endocrine and metabolic rhythms are closely associated with, and have therefore been classically attributed to, fluctuations in daily behaviors. However, various studies have directly challenged an obligatory relationship between the two, revealing that distinct $24 \mathrm{~h}$ endocrine and metabolic rhythms can be dissociated from behaviors. For example, oscillations in plasma cortisol and thyroid-stimulating hormone persist in human subjects when sleep is prevented through enforcement of a state of arousal during the night (Van Cauter et al. 1991, Van Cauter \& Copinschi 1999, Van Cauter \& Spiegel 1999). Twentyfour hour rhythms in epinephrine and plasminogen activator inhibitor 1 similarly persist in humans subjected to contiguous 20 or $28 \mathrm{~h}$ days (known as forced dyssychrony; Scheer et al. 2010, 2011, Shea et al. 2011, Scheer \& Shea 2014). With regards to metabolism, oscillations in circulating blood glucose levels persist during this forced dyssychrony protocol, highlighting that rhythms in carbohydrate metabolism are not simply secondary to alterations in physical activity and/or food intake during the day (Scheer et al. 2009). Collectively, these observations suggest that $24 \mathrm{~h}$ oscillations in specific endocrine and metabolic parameters are not driven solely by environmental/behavioral rhythms, but are instead mediated (at least in part) by endogenous mechanisms. One such likely candidate mechanism is the circadian clock.

The circadian clocks are cell autonomous molecular mechanisms that confer the selective advantage of anticipation, thereby allowing the cell/organ/organism to prepare for an extracellular stimulus/stress before its onset (Edery 2000, Takahashi et al. 2008). In doing so, this mechanism facilitates temporally appropriate responses, through orchestration of cellular processes over the course of the day. Circadian clocks (found within essentially all mammalian cells) comprise transcriptional-translational feedback loops, the components of which oscillate with a free-running periodicity of $\sim 24 \mathrm{~h}$ (Edery 2000 , Takahashi et al. 2008). A scheme illustrating the core components of the circadian clock mechanism is provided in Fig. 1. At the heart of the mammalian mechanism are two transcription factors, circadian locomotor output cycles kaput (CLOCK) and brain and muscle aryl hydrocarbon nuclear translocator (ARNT)-like 1 (BMAL1) (Gekakis et al. 1998, Hogenesch et al. 1998). Upon heterodimerization, CLOCK and BMAL1 bind to E-boxes in the promoter region of multiple target genes, including core components of the circadian clock mechanism. The latter include multiple period (PER) and cryptochrome (CRY) isoforms, which, upon accumulation of their translation products in the cytosol, heterodimerize and translocate back into the nucleus, subsequently inhibiting the transcriptional activity of CLOCK-BMAL1 (Miyamoto \& Sancar 1998, Zylka et al. 1998). A second wellcharacterized negative feedback loop involves REV-ERB $\alpha$ (encoded by the nuclear receptor subfamily 1 , group D, member 1 gene, NR1D1); accumulation of REV-ERB $\alpha$ protein results in repression of BMAL1 (ARNTL) transcription, through binding of REV-ERB $\alpha$ to the retinoid-related orphan receptor (ROR) response element within the BMAL1 promoter (Preitner et al. 2002). Additional feedback loops also exist, including involvement of deleted in esophageal cancer 1-2 (DEC1-2; Honma et al. 2002). Post-translational modifications (PTMs) are extremely important not only for appropriate operation of the clock mechanism itself (e.g. both phosphorylation and ubiquitination events are essential for temporal control of clock component protein turnover), but also for entrainment/synchronization of the mechanism with the environment (Lee et al. 2001, Harms et al. 2004). BMAL1 is an excellent example of a clock component whose activity is tightly controlled by PTMs (including phosphorylation, acetylation, ADP-ribosylation, SUMOylation, and O-GlcNAcylation), resulting in a multitude of PTM permutations over the course of the day (Kloss et al. 1998, Millar 2000, Cardone et al. 2005, Hardin \& Yu 2006, Asher \& Schibler 2011, Durgan et al. 2011). An imbalance in PTMs will result in aberrant regulation of the clock mechanism, as discussed in greater detail in subsequent sections.

In addition to understanding the inner workings of the circadian clock, it is important to appreciate the manner by which the mechanism is regulated, as well as the identity of the processes that it modulates (i.e. clock output). When considering regulation, it is important to note that clocks are separated into two broad categories based on location. The central circadian clock is located within a distinct region of the hypothalamus, known as the suprachiasmatic nucleus ( $\mathrm{SCN})$, whereas peripheral circadian clocks are located within non-SCN regions of the

Published by Bioscientifica Ltd. 


\section{Figure 1}

The mammalian circadian clock mechanism. The core circadian clock mechanism relies on a transcriptional-translational feedback loop comprising the transcription factors BMAL1 and CLOCK. On the positive side of loop, BMAL1 and CLOCK heterodimerize and bind E-box elements in PER and CRY genes that encode negative members of the feedback loop PER1-3 and CRY1-2. The PER and CRY proteins repress their own transcription by interfering with CLOCK-BMAL1 activity. A second feedback loop involving opposing actions of REV-ERB $\alpha$ and $\operatorname{ROR} \alpha$ nuclear receptors controls the rhythmic expression of BMAL1, which is essential for the generation of circadian clock rhythms. CLOCK-BMAL1 also promotes the transcription of many noncore clock and metabolic genes; a.k.a., clock-controlled genes. BMAL1, brain and muscle ARNT-like 1; CLOCK, circadian locomotor output cycles kaput; CCG, clock controlled gene; CRY1-2, cryptochrome 1-2; PER1-3, period 1-3; REV-ERBA or $\alpha$, nuclear receptor subfamily 1 , group $\mathrm{D} ; R O R A$ or $\alpha$, RAR-related orphan receptor alpha; $R R E$, retinoid response element. organism, including other regions of the CNS (Takahashi et al. 2008). Zeitgebers ('time-givers') are time cues that phase shift circadian clocks. Light is one of the most wellcharacterized zeitgebers, which resets the central SCN clock via the retino-hypothalamic tract (Berson 2003). In contrast, peripheral circadian clocks are influenced by various neurohumoral factors, including (in specific cases) direct innervation from the SCN (e.g. heart) (Scheer et al. 2001, Hirota \& Fukada 2004). Relevant to this review article, the quantity, quality, and timing of food intake differentially influence peripheral circadian clocks, with little or no impact on the SCN central clock (Damiola et al. 2000, Kohsaka et al. 2007, Bray et al. 2013). Output from the clock can manifest initially at the levels of both transcription and PTMs. In the former case, it has been estimated that between 8 and 13\% of a cell's transcriptome is regulated by cell autonomous clocks (Storch et al. 2002, Kornmann et al. 2007, Bray et al. 2008). Clock-controlled genes (CCGs) include, but are not limited to, genes encoding for proteins that impact transcription, translation, signaling, cell cycle/survival, and metabolism. The remainder of this review will focus on clock control of metabolic processes.

\section{Circadian clock control of metabolism}

A diverse number of metabolic pathways have now been shown to be regulated by the circadian clock, both directly (e.g. a key metabolic enzyme is regulated transcriptionally by the CLOCK-BMAL1 heterodimer) and indirectly (e.g. clock regulation of endocrine factor release influences metabolically active tissues in a time-of-day-dependent manner). Within this sub-section, we summarize what is currently known regarding circadian clock control of carbohydrate, lipid, protein, and $\mathrm{NAD}^{+}$metabolism.

\section{Clock control of carbohydrate metabolism}

Dramatic time-of-day-dependent oscillations in glucose metabolism are observed in both humans and rodent

Published by Bioscientifica Ltd. 
models, at both the whole body level and the organ/ cellular level. During periods of increased physical activity, non-insulin-mediated glucose utilization increases; the relative contribution of aerobic to anaerobic utilization being dependent upon exercise intensity (Rose \& Richter 2005, Alberts et al. 2006, Calvo et al. 2008). Similarly, food consumption results in insulin-mediated glucose disposal (Woerle et al. 2003). It is therefore not surprising that indirect calorimetry reveals increased glucose utilization during the awake period (relative to the sleep period). However, as highlighted in the preceding section, recent studies have strongly supported the concept that rhythms in glucose metabolism are not mediated purely by fluctuations in behaviors. Additional evidence includes the observation that circulating glucose levels increase before waking, in both humans and rodents, an event known as the dawn phenomenon (Bolli et al. 1984). Similarly, rhythms in blood glucose levels persist when rats are fasted (La Fleur et al. 1999). Collectively, these observations reveal an important role of an endogenous circadian mechanism in whole body glucose metabolism. Indeed, surgical ablation of the central clock (SCN) or genetic manipulation of circadian clock components disrupts glucose homeostasis (La Fleur et al. 1999, la Fleur et al. 2001). In the case of the dawn phenomenon, multiple studies suggest that the SCNparaventrciular nucleus-autonomic nervous system axis plays a critical role in daily rhythms in hepatic glucose output, as recently reviewed by Kalsbeek et al. (2014).

Glucose homeostasis is achieved through the coordinated regulation of exogenous (ingestion/digestion/ absorption) and endogenous (gluconeogenesis) glucose input vs disposal (utilization) mechanisms. Evidence exists that the hepatocyte circadian clock plays an important role in several processes involved in glucose homeostasis, including gluconeogenesis and glycogen turnover. In the latter case, hepatic glycogen levels display a diurnal variation in a variety of species including rats, mice, rabbits, guinea pigs, chickens, and human as highlighted in a study by Sollberger (1964). Interestingly, time-of-day-dependent rhythms in glycogen levels persist in fasted rodents (albeit at lower amplitude), suggesting that these rhythms are not simply secondary to feedingfasting cycles (Ishikawa \& Shimazu 1976). Not only do glycogen levels oscillate over the course of the day, but so do the activities of key glycogen metabolism enzymes; glycogen synthase displays maximum levels during the dark (active) phase in rodents, whereas glycogen phosphorylase peaks toward the end of the light (sleep) phase (Peret et al. 1976, Ishikawa \& Shimazu 1980). Evidence in support of circadian clock involvement in the mediation of these oscillations comes from recent studies by Doi et al. (2010), which have reported diminished oscillations in both hepatic glycogen levels and glycogen synthase expression/activity in Clock $^{\Delta 19}$ mutant mice. Similar to glycogen turnover, glucogenogenesis exhibits a diurnal variation; increased rates are observed at the sleep-to-wake phase transition (in comparison to the wake-to-sleep transition), which is paralleled by a diurnal rhythm of phosphoenolpyruvate carboxykinase (PEPCK) activity, a key regulatory enzyme in gluconeogenesis (Kida et al. 1980). Using hepatocyte-specific BMAL1 knockout mice, Lamia et al. (2008) found that the hepatocyte's circadian clock was critical for rhythms in PEPCK expression. More recently, Zhang et al. (2010) reported that the core clock component CRY modulates hepatic gluconeogenesis in a time-of-day-dependent manner through the regulation of $\beta$-adrenergic signaling and activation of cAMP response element-binding protein.

Both insulin-dependent and insulin-independent whole-body glucose disposal exhibits diurnal variations in humans and rodents (Whichelow et al. 1974, Lee et al. 1992, la Fleur et al. 2001). Extra-hepatic tissues, such as muscle, contribute in a significant manner to glucose homeostasis. Diurnal variations in glucose utilization of both skeletal and cardiac muscles persist ex vivo, suggesting that an intrinsic mechanism may contribute toward these rhythms (Leighton et al. 1988, Young et al. 2001). In the case of the heart, genetic disruption of the cardiomyocyte circadian clock abolishes time-of-daydependent rhythms in cardiac glucose oxidation, glycolysis, and glycogen synthesis, as well as protein $O$-GlcNAcylation (an indirect marker of flux through the hexosamine biosynthetic pathway; Durgan et al. 2011). More recently, Dyar et al. (2014) have reported decreased glucose uptake and oxidation by soleus and diaphragm muscles in skeletal myocyte-specific Bmal1 null mice, concomitant with dysregulation of pyruvate dehydrogenase. Collectively, these observations suggest that circadian clocks within cardiac and skeletal myocytes significantly influence glucose utilization.

Clock-mediated regulation of glucose homeostasis also involves the temporal regulation of endocrine factor release and sensitivity. Insulin and glucagon play important roles in the maintenance of blood glucose homeostasis (Voet \& Voet 2004). In vitro studies by Peschke \& Peschke (1998) showed that insulin secretion from isolated pancreatic rat islets display a circadian rhythm that originates within the islet. Further, plasma insulin concentrations in rats exhibit daily oscillations with distinct

Published by Bioscientifica Ltd. 
increments at every meal (Kalsbeek \& Strubbe 1998). Studies also show that disruption of the circadian clock causes impaired insulin secretion and consequent hypoinsulinemia (Marcheva et al. 2010, Coomans et al. 2013). Using melatonin receptor null mice as a model of circadian clock dysregulation, Muhlbauer et al. (2009) reported altered circadian rhythms of insulin transcripts and plasma insulin levels. Insulin sensitivity also exhibits a time-of-day dependence, which appears to be circadian clock dependent. For example, both glucose and insulin tolerance are impaired in SCN ablated rats, as well as Clock $^{\Delta 19}$ mutant and Bmal1 null mice (la Fleur et al. 2001, Rudic et al. 2004). Similarly, insulin signaling is impaired in various tissues isolated from germline Bmal1 null, Per2 mutant, and cardiomyocyte-specific Clock ${ }^{\Delta 19}$ mutant mice (Anea et al. 2009, Durgan et al. 2010, Carvas et al. 2012). In addition to insulin, glucagon also plays a crucial role in the regulation of blood glucose homeostasis, and has similarly been shown to display diurnal patterns of release (Gagliardino et al. 1978, Tasaka et al. 1980). A study by Ruiter et al. (2003) demonstrated that $24 \mathrm{~h}$ plasma glucagon concentrations are regulated by feeding and the circadian clock. Experiments by Bahr et al. (2011) demonstrate that melatonin (an important synchronizer of circadian rhythms) influences pancreatic glucagon expression, as well as peripheral glucagon action. Collectively, these observations raise the possibility that cell autonomous circadian clocks contribute toward rhythms in glucose homeostasis, through regulation of endocrine factors (e.g. insulin and glucagon) release and/or sensitivity.

\section{Clock control of lipid metabolism}

Similar to glucose, it is well documented that lipid metabolism displays time-of-day-dependent rhythms, which align with daily rhythms in behaviors, such as sleep-wake and feeding-fasting cycles. Significant evidence obtained using genetic mouse models of clock disruption supports the concept that rhythms in lipid metabolism are mediated by intrinsic molecular clocks. The purpose of this subsection is to provide a brief overview of current knowledge regarding clock control of lipid digestion/absorption, as well as oxidative and nonoxidative metabolism of lipids and fatty acids.

Uptake of dietary fat by the body involves mechanical emulsification, lipolytic breakdown, and absorption into intestinal epithelial cells. The digestive tract displays daily rhythms at multiple levels, including gastrointestinal motility, exocrine secretion, macronutrient absorption, and digestive enzyme activities. Using an in situ jejunal loop preparation and isolated primary enterocytes, Pan \& Hussain (2009) reported higher rates of cholesterol and lipid absorption during periods of high activity (dark phase) in mice and lower absorption during periods of low activity (light phase). Importantly, this study revealed that $\operatorname{Clock}^{\Delta 19}$ mutant mice absorbed similar amounts of macronutrients during both the day and night, indicating a loss of rhythm in intestinal absorption and supporting a role for the circadian clock in the regulation of nutrient absorption. Indeed, robust expression of clock genes in different regions and cell types in the gastrointestinal tract has been observed by several groups (Pardini et al. 2005, Hoogerwerf et al. 2007, Sladek et al. 2007). Furthermore, studies have shown that many of the genes involved in lipid uptake and metabolism in the intestine, including apolipoprotein $\mathrm{B}$ (Apob), Apo AIV (Apoa4), intestinal microsomal triglyceride transport protein (Mtp (Mttp)), and intestinal fatty acid binding protein ( $F a b p(F a b p 2)$ ), display diurnal rhythms (Pan \& Hussain 2007, 2009, Pan et al. 2010). Additional evidence for clock control of lipid digestion/absorption comes from the observations that mice with genetic ablation of nocturnin (a known clock controlled gene) are resistant to high-fat diet-induced obesity due to aberrant chylomicron excretion from the intestinal epithelial cells (Douris et al. 2011). While the importance of the intrinsic clock in the regulation of lipid metabolism-related functions in the intestinal tract is established, rhythms in these processes and others can be phase-shifted in response to restricted feeding regimens and attenuated by different lighting conditions (e.g. constant darkness or constant light), pointing to the importance of both feeding behavior and the light-dark cycle in time-of-day-dependent regulation of intestinal function (Pan \& Hussain 2009, Polidarova et al. 2011, Malloy et al. 2012). Moreover, Mukherji et al. (2013) have recently shown that proper functioning of the circadian clock in intestinal epithelial cells is necessary for maintaining homeostasis between the intestinal epithelium and gut microbiota. The importance of this relationship is showcased by work demonstrating that disrupting the intestinal circadian clock causes gut leakiness and hepatic inflammation (Swanson et al. 2011). Thus, continued investigation and improved understanding of the intestinal circadian clock are important especially with the newly recognized role of the intestinemicrobiome relationship in influencing metabolic syndrome (Vinje et al. 2014).

In addition to the processes described above, several lipid metabolism species exhibit daily rhythms. For example, circulating nonesterified fatty acids (NEFA) are known to display diurnal rhythms. Multiple studies have

Published by Bioscientifica Ltd. 
reported higher circulating levels of NEFA in rodents during their inactive phase (Stavinoha et al. 2004, Shostak et al. 2013). Similarly, humans have higher levels of NEFA at night due to increased lipolytic activity (Schlierf \& Dorow 1973). In support of an underlying circadian regulation of NEFA homeostasis, studies comparing circulating NEFA levels in fasted human volunteers revealed that plasma NEFA levels remained higher in the evening compared with the morning, despite lack of food intake (Carroll \& Nestel 1973, Gibson et al. 1975). Furthermore, a recent study by Dallmann et al. (2012) has found that plasma lipid levels remain rhythmic in human subjects maintained in constant dim light, even when food intake and wakefulness were kept constant (i.e. hourly iso-caloric food intake and sleep deprivation). Taken together, these studies provide strong evidence that rhythms in circulating lipid species (and presumably lipid metabolism) are not simply secondary to behavioral cycles.

Circadian regulation of triglyceride metabolism is achieved in part through the rhythmic gene expression of several enzymes involved in triglyceride biosynthesis (Shostak et al. 2013, Adamovich et al. 2014). Lipid biosynthesis is known to be regulated by sterol regulatory element-binding proteins (SREBP), a family of membranebound, basic helix-loop-helix leucine zipper transcription factors (Goldstein et al. 2006). Emerging studies reveal a transcriptional regulatory link between SREBP and the circadian clock. By the use of a combination of genetic loss- and gain-of-function experiments, Le Martelot et al. (2009) found that REV-ERB $\alpha$ regulates the daily rhythm in activity and expression of SREBP, as well as SREBP targets (e.g. fatty acid synthase and acetyl-CoA carboxylase $\alpha$ ), independently of feeding regimen. Regulation of lipid uptake, biosynthesis, and breakdown are tightly coupled. Therefore it is not surprising that lipid turnover and fatty acid $\beta$-oxidation are also diurnally regulated. Enzymes such as carnitine palmitoyltransferase 1 , medium-chain acyl-CoA dehydrogenase, adipose triglyceride lipase (ATGL), hormone-sensitive lipase (HSL), and diacylglycerol acyltransferase 2 (DGAT2) have been shown to exhibit circadian oscillations in various tissues at the gene expression level (Alenghat et al. 2008, Tsai et al. 2010, Filiano et al. 2013, Shostak et al. 2013). In support of clock control of these genes, Shostak et al. (2013) have shown that Hsl (Lipe) and Atgl (Pnpla2) oscillations are absent in white adipose tissue isolated from Bmal1 null mice, while Tsai et al. (2010) have reported loss of Dgat2 oscillations in the hearts of cardiomyocyte-specific Clock $^{\Delta 19}$ mutant mice. More recently, Bass et al. have proposed time-of-day-dependent regulation of hepatic $\beta$-oxidation through the circadian clock by protein acetylation (as discussed in greater detail in subsequent sections; Peek et al. 2013). Taken together, it is clear that cell autonomous circadian clocks likely regulate lipid metabolism at multiple levels.

\section{Clock control of protein and amino acid metabolism}

An important example of temporal regulation of biologic processes by cell autonomous circadian clocks is DNA synthesis and repair. DNA repair is increased during the active period, when oxidative stress is high, while DNA synthesis is restricted to the less active/sleep phase (Edery 2000). In doing so, the clock minimizes transmittance of mutations to daughter cells. An analogous form of regulation may occur for protein turnover. Oxidative stress is predicted to cause protein damage primarily during the active phase, while increased protein degradation and autophagy are observed during the less active/sleep phase (presumably as a means to remove damaged proteins/organelles, in anticipation of the subsequent active period). The nature of protein rhythms in protein synthesis appear to be less consistent; skeletal muscle net protein synthesis peaks during the active/awake phase, which is in marked contrast to cardiac muscle, for which protein synthesis peaks during the sleep/inactive phase (Garlick et al. 1973, Rau \& Meyer 1975). Consistent with these metabolic observations, several microarray studies have reported marked diurnal variations in genes known to modulate protein turnover, including ubiquitin ligases, proteasome subunits, and autophagy proteins and markers (Duffield et al. 2002, Reddy et al. 2006). Classically, stimulation of protein synthesis (e.g. skeletal muscle) and concomitant repression of protein degradation (e.g. liver) during the active/awake phase has been attributed to increased food intake at that period of time (Garlick et al. 1973). Indeed, circulating insulin levels (a potent anabolic signal) are increased during the active phase (Fulks et al. 1975, Rannels et al. 1975). Similarly, circulating amino acid levels are elevated during the awake phase, which act both as a substrate and stimulus for protein synthesis (Wurtman et al. 1968). Interestingly, diurnal variations in circulating amino acid levels persist both during fasting and consumption of protein-free diet, suggesting that ingestion of dietary protein during the active period is not mediating rhythms in circulating amino acids (or protein synthesis; Fernstrom et al. 1979). These observations raise the possibility that oscillations in protein degradation are independent of dietary status

Published by Bioscientifica Ltd. 
(i.e. feeding-fasting cycles), releasing amino acids into the circulation in a time-of-day-dependent manner.

Evidence has begun to accumulate, suggesting a role for circadian clocks in the regulation of protein turnover. Indeed, time-of-day-dependent turnover of circadian clock proteins is essential for the functioning of this mechanism. This is exemplified by the E3 ubiquitin ligases F-box and leucine-rich repeat protein 3 (FBXL3) and FBXL21, which are essential for turnover of CRY proteins (Yoo et al. 2013). Similarly, microarray analyses highlight multiple components of the ubiquitin/proteasome system as being regulated by circadian clock (Duffield et al. 2002, Reddy et al. 2006). One such component, ubiquitin-specific protease 2 (important for deubiquitination of proteins), is considered a direct Clock-Bmal1 target gene that influences hepatic gluconeogenesis (Molusky et al. 2012). Interestingly, this clock output gene oscillates in a number of additional metabolically active tissues, including skeletal and cardiac muscles (McCarthy et al. 2007, Bray et al. 2008). As highlighted above, insulin is a potent anabolic signal, and evidence suggests that cell autonomous circadian clocks influence insulin sensitivity; clock-mediated diurnal rhythms in insulin sensitivity may therefore contribute toward oscillations in protein turnover. Similarly, whether clock-driven oscillations in amino acid metabolism (particularly branched chain amino acids (BCAA)) impact protein turnover is an attractive hypothesis. Indeed, microarray analyses suggest regulation of the BCAA alpha ketoacid dehydrogenase by the circadian clock at the transcriptional level (ME Young, unpublished observations).

\section{Clock control of $\mathrm{NAD}^{+}$metabolism}

$\mathrm{NAD}^{+}$is traditionally considered as a key source of reducing equivalents for numerous oxidation-reduction reactions being interconverted between its oxidized $\left(\mathrm{NAD}^{+}\right)$and reduced (NADH) forms. However, $\mathrm{NAD}^{+}$ may also function as a cell signaling molecule via roles in PTMs; ADP-ribosylation and $\mathrm{NAD}^{+}$-dependent deacetylation. For example, $\mathrm{NAD}^{+}$activates sirtuin 1 (SIRT1) deacetylase thereby altering the acetylation status and presumably the function of cellular proteins (Imai et al. 2000, Landry et al. 2000). There are two metabolic pathways that control the levels of $\mathrm{NAD}^{+}$: the biosynthesis pathway from tryptophan and the salvage pathway (Imai 2010). Notably, the salvage pathway functions to preserve cellular $\mathrm{NAD}^{+}$levels when $\mathrm{NAD}^{+}$is used as a cofactor for signaling reactions. For example, when $\mathrm{NAD}^{+}$is used as a co-factor for SIRT1 it is degraded to nicotinamide (NAM). In the salvage pathway, NAM is converted to nicotinamide mononucleotide (NMN) by the enzyme nicotinamide phosphoribosyltransferase (NAMPT), the rate-limiting enzyme in the pathway. NMN is then reacted with ATP by the enzyme NAM/nicotinic acid mononucleotide adenylytransferase to regenerate $\mathrm{NAD}^{+}$. Importantly, the $\mathrm{NAD}^{+}$salvage pathway operates in a circadian fashion because NAMPT gene expression is regulated by CLOCKBMAL1 through DNA binding (Nakahata et al. 2009, Ramsey et al. 2009). The consequence of this is daily oscillations in $\mathrm{NAD}^{+}$and $\mathrm{NAD}^{+}$-dependent reactions (e.g. SIRT1 activity). Importantly, daily rhythms in NAMPT and $\mathrm{NAD}^{+}$are absent in tissues and cells from animal models with a nonfunctional circadian clock mechanism, and pharmacological inhibition of NAMPT activity also dampens $\mathrm{NAD}^{+}$oscillations (Nakahata et al. 2009, Ramsey et al. 2009, Peek et al. 2013). Together, these results demonstrate that the molecular clock plays an important role in the regulation of the levels of a key cellular metabolite, $\mathrm{NAD}^{+}$, which, in turn can feedback and regulate clock activity (see section on 'Acetylation'). With this said there are still gaps in this area of $\mathrm{NAD}^{+}$biology that require attention. For example, it is not clear what role the molecular clock plays in the regulation of different sub-cellular pools (nuclear, cytosolic, and mitochondrial) of $\mathrm{NAD}^{+}$. This is an important question as most studies have only looked at total cellular or whole tissue levels of $\mathrm{NAD}^{+}$and we now know that organelle compartmentation and microenvironments are critical aspects in control of metabolism. Furthermore, measurements done using isolated organelles (e.g. mitochondrial and/or nuclear fractions) may be invalid as $\mathrm{NAD}^{+}$content and/or the $\mathrm{NAD}^{+} / \mathrm{NADH}$ ratio will likely be altered during the sub-cellular fractionation procedure. However, investigations using a new mitochondrially targeted poly(ADP-ribose) polymerase 1 (PARP1) derivative as a tool for $\mathrm{NAD}^{+}$detection have shed some light into the mechanisms involved in generation of mitochondrial $\mathrm{NAD}^{+}$(Nikiforov et al. 2011). It is also important that investigators explicitly report the nutritional state (fed vs fasting), feeding strategy (ad libitum vs time-restricted), dietary formulations, and environmental conditions (light intensity and temperature) used in experimental studies, as all these factors most likely impact $\mathrm{NAD}^{+}$rhythms.

\section{Circadian clock regulation of mitochondrial bioenergetics}

Mitochondria are dynamic organelles that provide the majority of cellular energy needed for metabolic processes, through oxidative phosphorylation. In addition to ATP

Published by Bioscientifica Ltd. 
generation, mitochondria mediate the production of controlled reactive oxygen species (ROS) for redox signaling, regulate cytosolic $\mathrm{Ca}^{2+}$ levels, participate in the biosynthesis of amino acids and heme, generate heat via thermogenesis, and serve as a gatekeeper for apoptotic and necrotic signaling. Highlighting the importance of these processes and others in the maintenance of cellular homeostasis and health is the fact that mitochondrial damage and dysfunction are linked to numerous diseases. Because of the tight connection between circadian rhythms and metabolism, it has been proposed that various mitochondrial functions may be regulated by the circadian clock, and possibly may serve as a central coordinator between the clock and cellular energy metabolism (Langmesser \& Albrecht 2006). Although substantial evidence suggests that specific mitochondrial functions (e.g. carbohydrate oxidation) are circadian controlled, much less is known regarding time-of-daydependent changes in mitochondrial bioenergetics and the importance of the circadian clock in this vital process.

Daily oscillations in mitochondrial energy metabolism were first suggested by studies that examined gene expression in the SCN; Panda et al. (2002) reported circadian oscillations in the mRNA levels of several nuclear-encoded mitochondrial proteins involved in oxidative phosphorylation. Several databases of circadian gene expression (e.g. CircaDB (Circadian Expression Profiles Data Base), bioinf.itmat.upenn.edu/circa) provide evidence supporting circadian oscillations in specific respiratory chain subunits in various tissues from mice, including the SCN (Pizarro et al. 2013). Studies have also shown diurnal oscillations in other key bioenergetic parameters in the SCN, including mitochondrial membrane potential, cytochrome $c$ oxidase activity (Isobe $\mathrm{et} \mathrm{al}$. 2011), and coordination of mitochondrial $\mathrm{Ca}^{2+}$ handling in SCN astrocytes (Burkeen et al. 2011). Interestingly, cytochrome $c$ oxidase activity, as well as expression of subunits I and IV, is increased in the brain during wakefulness compared with sleep, presumably to meet increased energy demands when awake (Nikonova et al. 2005). Together, these findings support the concept of temporal organization of mitochondrial bioenergetics within important brain regions.

Accumulating evidence also supports circadian and/or diurnal oscillations in mitochondrial energy metabolism and associated oxidative pathways in peripheral tissues. For example, myocardial oxygen consumption exhibits daily oscillations in experimental rodent models (Young et al. 2001, Bray et al. 2008), purely during the active phase, when cardiac function is elevated. Yet, how these temporal changes in mitochondrial metabolism and bioenergetics are mediated is not as well understood. To address this question and assign the relative contribution of the molecular clock in these processes, recent studies have been performed using tissues, cells, and/or isolated organelles from mice deficient in core clock components. Notably, this work suggests that there are several different levels of clock control over mitochondrial metabolism, including both transcriptional and post-transcriptional mechanisms.

Using isolated mitochondria from germline Bmal1 null mice, Bass et al. reported reduced mitochondrial oxygen consumption when fatty acids were provided as an oxidizable substrate, but not in the presence of substrates that supply electrons directly to complex I or II of the mitochondrial respiratory chain (Peek et al. 2013). This finding suggests that a clock-mediated defect in $\beta$-oxidation, as opposed to respiratory chain components themselves, is likely responsible for lower respiration in liver mitochondria of Bmal1 null mice. Additional experiments from this study suggest that reduced oxidative metabolism was associated with hyperacetylation of mitochondrial proteins in Bmal1 null mice, potentially due to low levels of $\mathrm{NAD}^{+}$and decreased activity of SIRT3 (the mitochondrial $\mathrm{NAD}^{+}$-dependent deacetylase). Importantly, repletion of $\mathrm{NAD}^{+}$with NMN normalized protein acetylation and partially restored respiration rates in mitochondria from Bmal1 null mice. Given that $\mathrm{NAD}^{+}$salvage is directly controlled by cell autonomous clocks, these observations suggest that circadian control of fatty acid $\beta$-oxidation is mediated by rhythmic oscillations in $\mathrm{NAD}^{+}$, SIRT3 activity, and posttranslational acetylation of mitochondrial proteins. In support of this, Sassone-Corsi et al. (Masri et al. 2013) have also reported that many mitochondrial proteins are differentially acetylated and linked to circadian alterations of the liver metabolome. Together, these results suggest that the circadian clock regulates mitochondrial energy metabolism, in part, by a nontranscriptional mechanism, namely PTM (i.e. acetylation) of proteins.

Similar to numerous metabolic processes, mitochondrial biogenesis is controlled transcriptionally by various nuclear receptors, including estrogen-related receptor alpha and nuclear respiratory factor 1 (NRF1) and NRF2. Genetic control over mitochondrial biogenesis by these factors is coordinated by the peroxisome proliferator-activated receptor- $\gamma$ coactivator 1 (PGC1) family of transcriptional coactivators. PGC1 $\alpha$ and PGC1 $\beta$ dock with the DNA-binding transcription factors NRF1 or NRF2 to stimulate the metabolic gene network involved in

Published by Bioscientifica Ltd 
mitochondrial biogenesis and oxidative phosphorylation (Scarpulla 2008). Expression of these coactivators is increased in response to a variety of environmental inputs, nutritional stimuli, mitochondrial outputs (e.g. ROS and/or $\mathrm{Ca}^{2+}$ ), and circadian signals (Lin 2009). Notably, rhythmic expression of PGC1 $\alpha$ and PGC1 $\beta$ mRNA and protein has been reported in several peripheral tissues, and mice deficient in these coactivators have lower levels of metabolic and mitochondrial genes (Liu et al. 2007, Sonoda et al. 2007). In addition to PGC1, a second level of transcriptional control over mitochondrial metabolism that is linked to the molecular clock is the nuclear receptor REV-ERB $\alpha$; a known repressor of BMAL1 transcription and other target genes (Duez \& Staels 2009). Duez et al. (Woldt et al. 2013) showed that REV-ERB $\alpha$ deficiency in skeletal muscle impairs mitochondrial biogenesis and lowers the content of respiratory chain subunit genes resulting in decreased mitochondrial oxygen consumption and reduced exercise endurance in mice. Conversely, pharmacological activation of REV-ERB $\alpha$ significantly improved mitochondrial respiration by stimulating mitochondrial biogenesis through the AMP-dependent protein kinase (AMPK)-SIRT1-PGC1 $\alpha$ pathway (Woldt et al. 2013). A novel role of REV-ERB $\alpha$ in mitochondrial metabolism has also been shown where REV-ERB $\alpha$ functions as a negative regulator of adaptive thermogenesis via repression of mitochondrial uncoupling protein 1 in brown adipose tissue (Gerhart-Hines et al. 2013). Thus, PGC1 and REVERB may serve unique roles as potential integrators of the circadian clock and mitochondria to fine-tune mitochondrial metabolism under changing environmental conditions.

The studies described earlier raise the question as to whether mitochondrial content oscillates in a time-ofday-dependent manner with a control of mitochondrial content regulated by a balance between mitochondrial biogenesis and mitochondrial turnover (e.g. mitophagy and/or the Lon protease). Clearly, the work of Duez et al. (Woldt et al. 2013) indicates that some parameters of mitochondrial biogenesis and turnover are negatively affected in skeletal muscle in REV-ERB $\alpha$ null mice; however, the time-of-day dependence of these two key metabolic programs was not examined in this study. Further, these alterations in mitochondrial function could be independent of the circadian clock as REV-ERB is a transcription factor for multiple noncircadian target genes. Furthermore, Peek et al. (2013) showed that the levels of several markers of mitochondrial biogenesis (e.g. mtDNA content and PGC1 $\alpha$ protein) were normal in liver of Bmal1 null mice. Nonetheless, these markers were only measured at one or two time points during the day; thus, it is difficult to draw a solid conclusion from this study as too few time points were measured. Thus, more comprehensive studies are required to address this question, especially in a tissue-specific manner, as it is anticipated that different tissues will have different regulatory mechanisms due to tissue-specific rates of mitochondrial turnover (Lipsky \& Pedersen 1981, Miwa et al. 2008). With this said, determination of the time-of-day dependence in mitochondrial quality control is not a trivial undertaking. In addition to biogenesis and mitophagy, studies need to consider time-of-day changes in the cellular mitochondrial network (governed by mitochondrial fusion and fission), as alterations in mitochondrial dynamics also impact cellular bioenergetics.

Additional examples illustrating the importance of the molecular clock in the regulation of mitochondrial function include pancreatic $\beta$-cell dysfunction in germline Bmal1 null mice (Lee et al. 2011). Impairment in insulin secretion in Bmal1 null mice islets appears to occur due to a consequence of lowered mitochondrial membrane potential and ATP generation (Lee et al. 2011). Investigation of skeletal muscle mitochondria in Bmal1 null and Clock $^{\Delta 19}$ mutant mice reveal reduced volume, altered morphology, and increased uncoupled respiration (Andrews et al. 2010). Moreover, heart mitochondria isolated from cardiomyocyte-specific Clock $^{\Delta 19}$ mutant mice exhibit decreased state 3 and state 4 respiration in the presence of multiple substrates (Bray et al. 2008).

In summary, the studies presented in this section provide compelling evidence that normal mitochondrial respiratory chain function and bioenergetics are dependent on the molecular clock. We hypothesize that the circadian clock synchronizes mitochondrial ATP production in a time-of-day-dependent manner, to meet daily fluctuations in cellular energy demands. This appears to be achieved by a variety of transcriptional and posttranslational dependent mechanisms. For example, circadian control over mitochondrial turnover (a balance between biogenesis, mitophagy, and fusion/fission) should be considered as a potential mechanism regulating cellular bioenergetics. Moreover, recent evidence has suggested that clock control over mitochondrial fatty acid oxidation is mediated, in part, by metabolite cycling (e.g. $\mathrm{NAD}^{+}$) and protein acetylation (Peek et al. 2013). Future studies should be directed at characterizing the influence of other metabolites and PTMs (e.g. nitrosation) on time-of-day dependent changes in cellular bioenergetics. A disrupted clock would also desynchronize the expression of respiratory chain subunits, resulting in a

Published by Bioscientifica Ltd. 
damaged electron transport system. One consequence of an improperly 'put together' respiratory chain might include slippage in electron flow among the complexes resulting in increased ROS production and decreased ATP production. Thus, perturbations in the circadian clock may be a key initiating factor in diseases linked to mitochondrial damage.

\section{Role of circadian clocks in anticipating metabolic demands}

The concept of anticipation is not new to the field of endocrinology, particularly in the context of metabolism. The 'fight-or-flight' response is a classic example, in which a rise in adrenaline levels facilitates mobilization of intracellular energy stores (i.e. glycogen and triglyceride) in anticipation of imminent physical activity. A second example includes the 'dawn phenomenon', characterized by an elevation in blood glucose levels before awaking (secondary to alterations in hepatic glucose output and insulin sensitivity). Although the exact biological significance of this phenomenon is unknown, it has been hypothesized that the rise in blood glucose is in anticipation of increased energetic demand upon awaking. Despite appreciation of the importance of anticipation, and the regulation of metabolism by circadian clocks, several fundamental questions remain unanswered regarding the interplay between extrinsic (e.g. endocrine factors) and intrinsic (e.g. circadian clock) factors, and their contribution toward time-of-day-dependent metabolic homeostasis. This includes an understanding of how a cell/organ is able to simultaneously anticipate seemingly opposing metabolic scenarios (e.g. successful forage for food vs prolongation of the sleep phase fast). This subsection proposes an evidence-based hypothetical model in an attempt to begin addressing these questions.

In general terms, organisms have two 'major' behavioral oscillations to contend with on a daily basis. These are active/inactive and feeding/fasting rhythms. During the awake period, increased physical activity associated with foraging for food, avoidance of predation, and/or reproduction are energetic demands that are anticipated to occur, even if the animal in the wild is not successful in its forage for food. Organisms that anticipate this scenario (i.e. physical activity/energetic demand rhythms independent of feeding status) would undoubtedly have an evolutionary-selective advantage. At the same time, it is essential that upon successful foraging of food, cells/ organs maintain adequate metabolic flexibility, facilitating efficient storage of nutrients (in anticipation of the next period of fasting). We hypothesize that circadian clocks have an integral relationship with endocrine factors, enabling anticipation of both fasting and feeding during the active period. In this study, discussion will focus initially on the greater selective pressure (i.e. the less favorable scenario of unsuccessful foraging for food during the active period). The model in Fig. 2 predicts that cell autonomous clocks directly regulate metabolic processes, promoting maximal oxidative metabolism capacity during the awake period (particularly in muscle), in anticipation of increased energetic demands during continued foraging for food; conversely, these processes are repressed during the sleep phase. Cell autonomous circadian clocks within metabolically active tissues would therefore be predicted to induce metabolic genes/proteins facilitating glucose uptake, glycogen utilization, and oxidative metabolism during the awake phase. Similarly, clock-mediated sensitization to 'physical activity' signals (e.g. $\beta$-adrenergic stimulation) would amplify metabolic responsiveness (i.e. endocrine-clock interaction). Conversely, reversal of circadian clock-mediated effects during the sleep phase would minimize excessive energy expenditure and oxidative stress during the sleep phase (a time at which organelle and cellular repair likely occurs). Cell autonomous circadian clocks would enable metabolically active tissues to 'hedge their bets', by concomitantly increasing sensitivity to insulin during the active phase. Should the animal be successful in its forage for food at that time, stimulus (insulin) and responsiveness (insulin sensitivity) would be synchronized, facilitating efficient uptake and storage of substrates. Thus, cell autonomous circadian clocks are predicted to have direct (increase maximal metabolic capacity during the active period) and indirect (to simultaneously sensitize to 'activity' and 'feeding' signals) modes of action.

For the hypothetical model depicted in Fig. 2 to be accurate, tissues with a high energetic demand during the active phase (e.g. muscle) would be expected to exhibit circadian clock-mediated augmentation of substrate uptake and oxidative capacity, as well as $\beta$-adrenergic and insulin sensitivity, during the active period. Evidence exists in support of this hypothesis, particularly in the heart. AMPK activity oscillates markedly in the hearts of WT mice, but not of cardiomyocyte-specific Clock $^{\Delta 19}$ mutant mice, paralleled by clock-dependent rhythms in glucose uptake and utilization. Should fatty acid availability increase during the active phase (due to, for example, prolongation of the sleep phase fast) increased AMPK activity at this time would facilitate $\beta$-oxidation. Both cardiac $\beta$-adrenergic responsiveness and activation

Published by Bioscientifica Ltd. 
A Active phase - unsuccessful forage for food

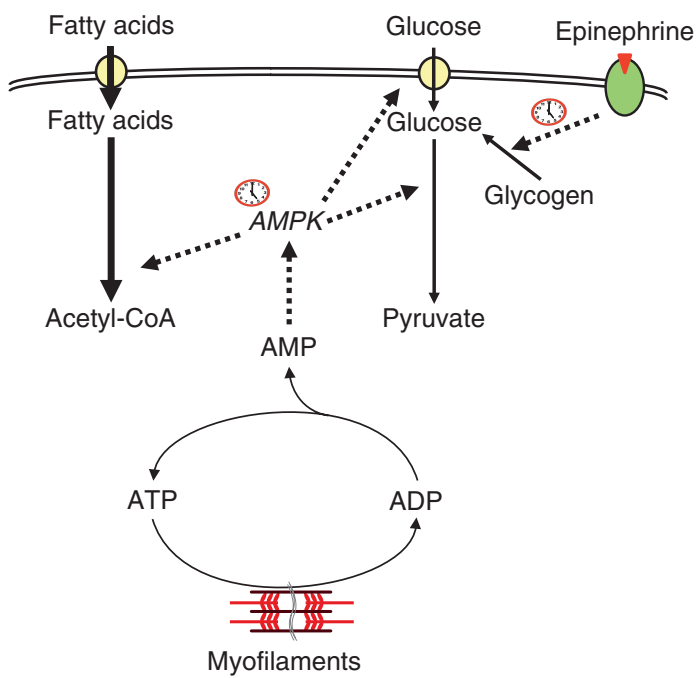

B Active phase - successful forage for food

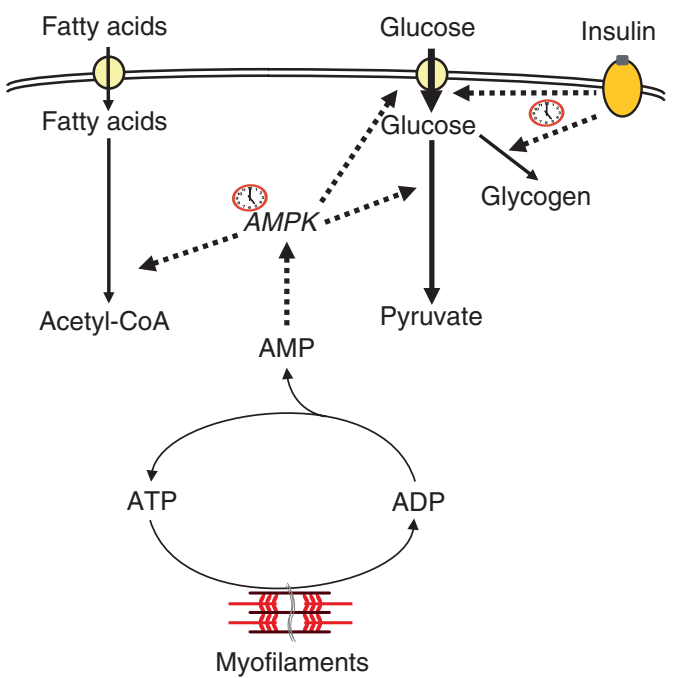

Figure 2

Hypothetical role for the circadian clock in anticipation of fasted (A) vs fed (B) states. As outlined in the text, we hypothesize that the circadian clock within skeletal and/or cardiac myocytes anticipate increased energetic demand during the active period, through mechanisms such as AMPK activation (possibly through the NAMPT/SIRT1/LKB1/AMPK axis), which promotes substrate uptake and utilization. Similarly, clock-mediated augmentation of $\beta$-adrenergic sensitivity during the active period would facilitate efficient energy store breakdown, for continued contraction. Should the animal be successful in its forage for food (B), increased clockmediated augmentation of insulin sensitivity during the active phase would promote efficient uptake and storage of nutrients. Clock symbol represents a clock-controlled process; dashed lines indicate positive regulation on a process; thickness of solid lines represents relative flux through a pathway. Acetyl CoA, acetyl coenzyme A; AMPK, AMP-activated protein kinase; LKB1, liver kinase B1; NAMPT, nicotinamide phosphoribosyltransferase; SIRT1, sirtuin 1. of insulin signaling components are increased during the active phase, in a clock-dependent manner. More recently, we have found that the phosphoinositide 3-kinase component p85a is under direct clock control (ME Young, unpublished observations), in a manner consistent with clock increased insulin sensitivity during the active phase (in anticipation of successful foraging of food). Collectively, these observations suggest that cell autonomous circadian clocks are an essential link between endocrinology and metabolic homeostasis.

\section{Metabolic regulation of the molecular circadian clock}

It is now widely accepted that metabolism is not only an output from the clock, but that various metabolic processes influence function and timing of the clock (Peek et al. 2012, Sahar \& Sassone-Corsi 2012). An excellent example of this is protein turnover. For the clock to function, components must be synthesized and degraded in a time-of-day-dependent fashion; pharmacological interference with protein turnover drastically impairs clock function. The purpose of this subsection is to review current knowledge regarding the impact of metabolism on the circadian clock. We will focus on redox status, acetylation, ADP-ribosylation, phosphorylation, $O$-GlcNAcylation, heme, and reactive species (a number of which are summarized in Fig. 3).

\section{Redox status}

One of the earliest studies supporting the concept that metabolism can affect clock function investigated the role of cellular redox state (Rutter et al. 2001). This work showed that DNA binding of the CLOCK-BMAL1 heterodimer could be influenced by the relative ratio of $\mathrm{NAD}(\mathrm{P}) \mathrm{H}$ and $\mathrm{NAD}(\mathrm{P})^{+}$. Rutter et al. (2001) demonstrated that high levels of $\mathrm{NAD}(\mathrm{P}) \mathrm{H}$ increased binding of CLOCK-BMAL1 (or neuronal PAS domain protein 2 (NPAS2)-BMAL1) to DNA E-box motifs, whereas $\mathrm{NAD}(\mathrm{P})^{+}$decreased binding. Notably, high levels of lactate dehydrogenase A (LDHA) mRNA accumulate in cells transfected with expression vectors encoding NPAS2 and BMAL1, demonstrating that $L D H A$ is a transcriptional target of NPAS2-BMAL1. LDH plays a critical role in the maintenance of cellular redox state, as its co-factor for the reaction catalyzing the conversion of lactate to pyruvate (or vice versa) is $\mathrm{NAD}^{+}$ (or NADH). Thus, $L D H$, a target gene of NPAS2-BMAL1 has the ability to feedback and regulate clock activity by changing the cellular redox potential in vivo. Recent work by Yoshii et al. (2013) has confirmed that DNA binding

Published by Bioscientifica Ltd 


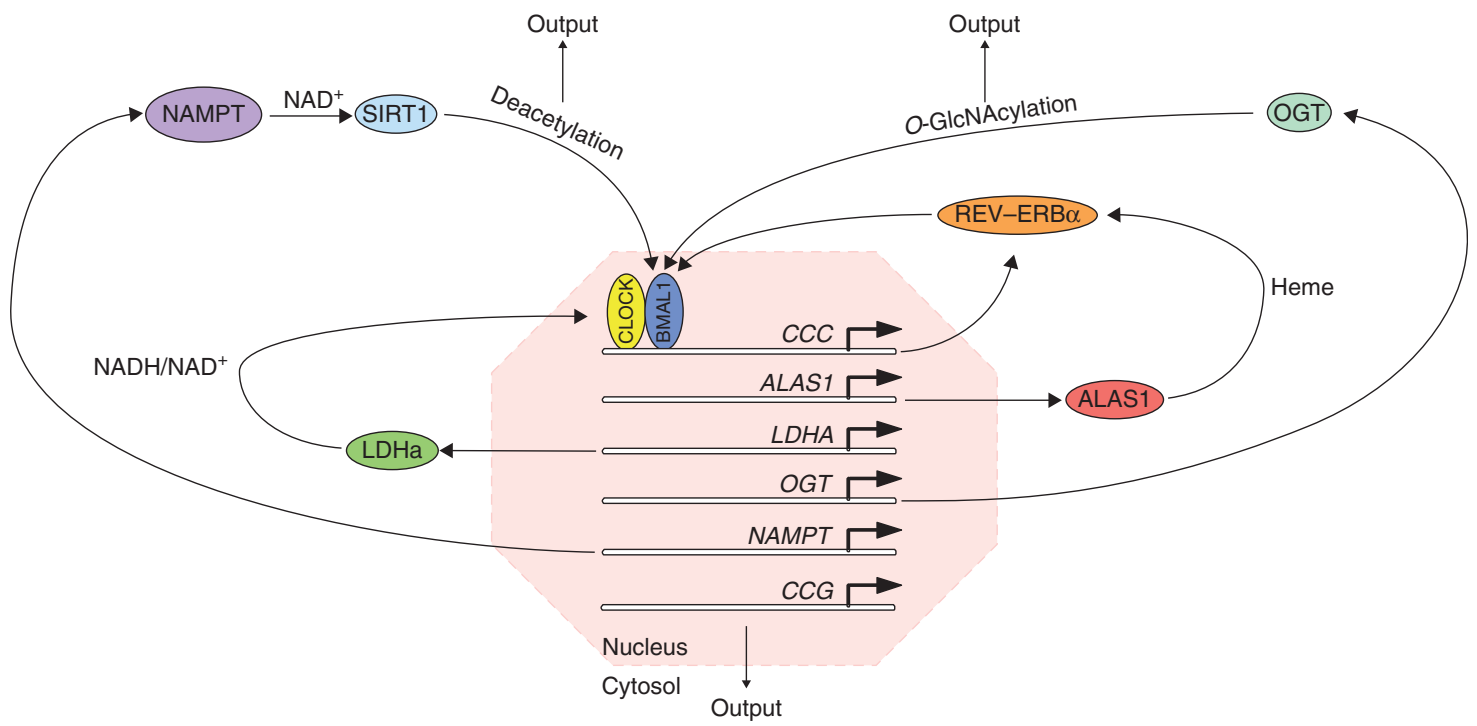

Figure 3

Metabolic feedback loops of the mammalian circadian clock. Clockmediated induction of ALAS1, LDHa, OGT, and NAMPT, likely form feedback loops through regulation of heme biosynthesis, redox status, protein $\mathrm{O}$-GIcNAcylation, and protein deacetylation respectively (for additional details, please see relevant text within the 'Metabolic regulation of the molecular circadian clock' subsection. ALAS1, $\delta$-aminolevulinate

of NPAS2-BMAL1 is enhanced by $\mathrm{NAD}(\mathrm{P}) \mathrm{H}$; however, $\mathrm{NAD}(\mathrm{P})^{+}$had no effect on DNA binding: these studies also localized the NAD $(\mathrm{P}) \mathrm{H}$ enhancement binding site to the N-terminal (1-61 residues) region of NPAS2. Together, these studies strongly support the concept that transcriptional activity of the clock is responsive to daily fluctuations in NAD(P)H levels.

\section{Acetylation}

The influence of $\mathrm{NAD}^{+}$on the clock is highlighted further by work showing that the $\mathrm{NAD}^{+}$-dependent deacetylase SIRT1 has an impact on clock activity. As discussed in previous sections, intracellular $\mathrm{NAD}^{+}$levels oscillate significantly due to NAMPT regulation by CLOCKBMAL1. More recently, evidence suggests that SIRT1 deacetylates BMAL1 and PER2 in an $\mathrm{NAD}^{+}$-dependent manner (Asher et al. 2008, Nakahata et al. 2008), thereby counteracting the known acetylase activity of CLOCK (which is important for normal clock function) (Doi et al. 2006). SIRT1 also regulates $\mathrm{NAD}^{+}$levels because it is recruited to the NAMPT promoter (Nakahata et al. 2009, Ramsey et al. 2009). Therefore, circadian $\mathrm{NAD}^{+}$oscillations influence the function of the molecular clock indirectly by controlling rhythms in SIRT1 activity. Evidence exists suggesting that $\mathrm{NAD}^{+}$levels influence synthase; BMAL1, brain and muscle ARNT-like 1; CLOCK, circadian locomotor output cycles kaput; CCC, circadian clock components; CCG, clock controlled genes; LDHA, lactate dehydrogenase A; NAMPT, nicotinamide phosphoribosyltransferase; OGT, O-GICNAc transferase; REV-ERB $\alpha$, nuclear receptor subfamily 1, group D; SIRT1, sirtuin 1 .

the circadian clock in vivo; Sahar et al. (2011) reported that Cd38 null mice (with chronically elevated $\mathrm{NAD}^{+}$levels) exhibited disrupted circadian behavior (e.g. shortened period length and altered rest-activity rhythms) and altered clock and metabolic gene expression in liver.

\section{ADP-ribosylation}

Another $\mathrm{NAD}^{+}$-mediated mechanism for clock regulation has been described, which involves PARP1 (Asher \& Schibler 2011), a protein known to catalyze the transfer of ADP-ribose units from $\mathrm{NAD}^{+}$to various target proteins (Kraus \& Hottiger 2013). Asher et al. (2010) showed that PARP1 binds to and poly ADP-ribosylates CLOCK, thereby decreasing its binding with DNA. Conversely, loss of PARP1 enhances CLOCK-BMAL1 binding to DNA, which was found to alter the expression of known clock output genes. While PARP1 activity exhibits diurnal changes, this activity rhythm persists in livers following disruption of the hepatocyte clock, suggesting mediation by extrinsic factors (Asher et al. 2010). Indeed, experiments show that PARP1 activity is potentially regulated by feeding time, as the peak in poly ADP-ribosylation of PARP1 can be shifted by restricted feeding protocols (Asher et al. 2010). Therefore, unlike that of SIRT1, circadian oscillations in $\mathrm{NAD}^{+}$are unlikely to be responsible for PARP1 activity

Published by Bioscientifica Ltd 
rhythms, as $\mathrm{NAD}^{+}$, NAMPT expression, and PARP1 activity oscillations are not synchronized and PARP1 activity rhythms do not require CLOCK-BMAL1 activity (Asher et al. 2010). Nevertheless, these findings support a mechanism whereby PARP1 activity links nutritional status to phase shifting of peripheral clocks.

\section{AMP-dependent protein kinase}

AMPK is another key metabolic sensor central for the transmission of nutrient and energy-dependent signals to the molecular clock (Jordan \& Lamia 2013). AMPK functions as an energy sensor, being exquisitely sensitive to the AMP/ATP ratio in cells. When AMP levels are elevated, structural changes in AMPK enhance phosphorylation by liver kinase B1 (LKB1), resulting in activation. AMPK catalyzes the phosphorylation of the clock repressor proteins CRY1 and CRY2, targeting them for proteasomal degradation (Lamia et al. 2009). AMPK also targets PER proteins for degradation by phosphorylating casein kinase $1 \varepsilon(\mathrm{CK} 1 \varepsilon)$, which subsequently stimulates CK1ع-mediated phosphorylation of PERs (Um et al. 2007). Ampk $\alpha$ null mice have increased PER2 levels (Um et al. 2007), supporting the hypothesis that AMPK impacts the circadian clock in vivo. Conversely, the AMPK activators AICAR (Um et al. 2007) and metformin (Barnea et al. 2012) shift the phase of the liver clock. A mechanistic connection also appears to exist between SIRT1 and AMPK; studies show that SIRT1 deacetylates LKB1 influencing the activity, localization, and ability of LKB1 to activate AMPK (Lan et al. 2008). Collectively, these observations have led to the hypothesis that AMPK may re-set (i.e. entrain) peripheral circadian clocks during specific physiologic and pathophysiologic states.

\section{O-GICNAcylation}

Modification of proteins by $O$-linked $\beta$ - $N$-acetylglucosamine (O-GlcNAc) has emerged as a new regulator linking metabolism to the circadian clock. Reminiscent of phosphorylation, O-GlcNAcylation of proteins is regulated by the balance between $O$-GlcNAc transferase (OGT; which catalyzes the addition of O-GlcNAc to protein serine and threonine residues) and $O$-GlcNAcase (OGA; which hydrolyzes O-GlcNAc residues) (Hart et al. 2011). The substrate for O-GlcNAcylation is the highenergy compound UDP- $\mathrm{N}$-acetylglucosamine; a product of the hexosamine biosynthetic pathway. Studies by Young et al. showed coordinated diurnal variations in glucose metabolism, OGT, and OGA leading to peak
$O$-GlcNAcylation of cardiac proteins in the middle of the active (dark) phase (Durgan et al. 2011). These diurnal changes were absent in hearts of cardiomyocyte-specific Clock $^{\Delta 19}$ mutant mice, suggesting that these pathways are under direct clock control. Importantly, they demonstrated that BMAL1 is a target for O-GlcNAcylation and that pharmacological inhibition of OGA shifted the phase of the heart clock (Durgan et al. 2011). Related studies in Drosophila and mice also support a role of this PTM in regulation of the circadian clock, as O-GlcNAcylation of CLOCK and PER2 affects their transcriptional activities and alters the timing of the clock (Kim et al. 2012, Kaasik et al. 2013). Furthermore, O-GlcNAcylation prevents BMAL1 and CLOCK degradation by inhibiting their ubiquitination. In addition, liver-specific knockdown of OGT decreased hepatic BMAL1 transcripts late in the active (dark) phase and altered diurnal rhythms in glucose homeostasis (by affecting hepatic gluconeogenic gene expression) (Li et al. 2013). Together, these studies demonstrate that $O$-GlcNAc is a novel metabolic signal connecting metabolism and the circadian clock.

\section{Heme and reactive species}

The iron-containing protein, heme, influences clock function by binding to distinct clock components, including CRY1-2, NPAS2, and REV-ERB $\alpha$ (Burris 2008). Heme binding to REV-ERB nuclear receptors causes the recruitment of the nuclear receptor co-repressor (NCoR) histone deacetylase (HDAC) co-repressor complex to REV-ERB homodimers, leading to the repression of target genes (e.g. BMAL1; Yin \& Lazar 2005, Raghuram et al. 2007). The rate-limiting enzyme in heme biosynthesis, $\delta$ aminolevulinate synthase (ALAS1), exhibits a circadian rhythm at the gene level (Rogers et al. 2008) due to activation by NPAS2 and PGC1 $\alpha$, resulting in circadian clock-mediated oscillations in heme levels (Kaasik \& Lee 2004, Handschin et al. 2005). Importantly, ligation of heme to REV-ERB $\alpha$ in turn inhibits its own biosynthesis through REV-ERB $\alpha$-mediated inhibition of PGC1 $\alpha$ (Wu et al. 2009). This feedback loop functions to tightly maintain heme levels within a physiologic range in the cell. Thus, heme metabolism appears to constitute an additional metabolic feedback loop of the molecular clock.

An important characteristic of heme is its ability to bind gaseous signaling molecules including nitric oxide (NO), carbon monoxide (CO), and hydrogen sulfide $\left(\mathrm{H}_{2} \mathrm{~S}\right)$. The ability of gaseous signaling molecules to influence clock function was first recognized when binding of $\mathrm{CO}$ to the heme in NPAS2 decreased the formation of

Published by Bioscientifica Ltd. 
NPAS2-BMAL1 heterodimers in vitro (Dioum et al. 2002). Transcriptional regulation by REV-ERBs may be similarly influenced by interaction of heme with these gaseous molecules. Pardee et al. (2009) reported that the NO donor (DETA NONOate) blocked REV-ERB-mediated repression of gene transcription in HEK 293 cells. Work by Gupta \& Ragsdale (2011) have expanded on this novel concept by showing that the redox state of a thiol-disulfide redox switch controls heme affinity to the ligand-binding domain in REV-ERB $\beta$. This study demonstrated that formation of a disulfide bond between Cys-384 and Cys374 in the REV-ERB $\beta$ ligand-binding domain lowers the affinity for heme, whereas the reduced dithiol between these two Cys residues binds heme more tightly. As thioldisulfide switches are sensitive to PTM by ROS and reactive nitrogen species, conditions involving oxidative stress may cause perturbation of REV-ERB-controlled pathways including the clock. With regards to $\mathrm{H}_{2} \mathrm{~S}$, much less is known about the impact this signaling molecule may have on the molecular clock. Incubation of cultured mouse hepatocytes with sodium hydrosulfide was shown to maintain oscillations of distinct clock genes (Shang et al. 2012). Furthermore, inhaled $\mathrm{H}_{2} \mathrm{~S}$ was found to increase cardiac Per1 gene expression relative to rats exposed to room air (SM Bailey, unpublished observations). Together, the results from these studies strongly suggest that the interaction of heme with multiple reactive gaseous species may be important for the maintenance of clock function, whereas aberrant production of reactive species could potentially dysregulate the clock. The importance of this level of control is strengthened further by recent reports that peroxiredoxin, the main hydrogen peroxide detoxification enzyme, has a $24 \mathrm{~h}$ cycle in the oxidation state of its catalytic site (Edgar et al. 2012). Indeed, future studies should be aimed at understanding circadian regulation of the enzymatic pathways responsible for the production and removal of the gaseous signaling molecules and other reactive species (e.g. ROS), as mounting evidence support their role in clock function.

\section{Cardiometabolic consequences of disrupted circadian rhythms}

It has become clear that metabolism and the circadian clock are inseparably interlinked (Fig. 3). As highlighted above, the circadian clock not only regulates metabolism, but in turn, metabolism influences the circadian clock. In certain instances, metabolic processes have emerged as integral components of the mammalian circadian clock. It is therefore not surprising that disruption or misalignment among internal biological clocks and the external environment, or among internal clocks in different tissues, perturbs metabolic homeostasis, leading to metabolic diseases. In this context, cardiometabolic disease as a consequence of circadian misalignment in humans has received the greatest attention in individuals that perform night and/or shift work; night-shift workers have greater risk for obesity, diabetes mellitus, and cardiovascular disease compared with day-shift counterparts (see reviews by Knutsson (2003) and Esquirol et al. (2011)). More recently, studies on both animal models and humans suggest that circadian misalignment occurs during meal feeding, ethanol consumption, obesity, and diabetes, leading to speculation that aberrant circadian clock function during these conditions potentially contributes toward the etiology of cardiometabolic dysfunction and disease. This sub-section will consider the evidence for each of these.

\section{Shift work}

Night-shift workers often exhibit dyslipidemia (e.g. high triglycerides and/or low HDL cholesterol), increased postprandial serum glucose and insulin (Lund et al. 2001), and increased circulating levels of several biomarkers of inflammation (Sookoian et al. 2007), associated with increased incidence of obesity and diabetes (Karlsson et al. 2001, Nagaya et al. 2002, Morikawa et al. 2005, Kroenke et al. 2007, Copertaro et al. 2008, De Bacquer et al. 2009, Lin et al. 2009, Burgueno et al. 2010, Chen et al. 2010). Controlled laboratory-based studies clearly showed that circadian misalignment disrupts metabolism in humans. For example, Scheer et al. (2009) induced circadian misalignment in healthy adults by using an 11-day forced dyssynchrony protocol consisting of repeated ' $28 \mathrm{~h}$ days'; during this protocol, all subjects ate four isocaloric meals each ' $28 \mathrm{~h}$ day' and slept at all phases of the circadian cycle. The results showed that circadian misalignment (defined as eating and sleeping $12 \mathrm{~h}$ out of phase from their habitual times) increased circulating glucose and insulin, decreased leptin, and increased blood pressure. Indeed, some subjects in this study exhibited pre-diabetic symptoms in response to circadian misalignment. More recently, Van Cauter et al. have reported augmentation of insulin resistance in sleep-deprived subjects following circadian misalignment (Leproult et al. 2014). Together, these results support the concept that circadian misalignment in shift workers may contribute toward development of cardiometabolic disease.

The influence of sleep disturbances (e.g. too little sleep) and/or psychosocial stressors should not be

Published by Bioscientifica Ltd. 
overlooked as additional risk factors for metabolic disease in shift workers (Clougherty et al. 2010, Bannai \& Tamakoshi 2014). For example, a combination of sleep deprivation and circadian disruption ('28 h days') caused decreased metabolic rate and increased postprandial glucose in healthy adults (Buxton et al. 2012). Sleep deprivation and sleep restriction alone have been shown to alter endocrine regulators of glucose and energy metabolism, which may lead to insulin resistance, obesity, and other pathologies (Zizi et al. 2010, Lucassen et al. 2012). Studies show that acute sleep restriction (three consecutive nights of shortened sleep $-4 \mathrm{~h}$ of sleep/night) reduced insulin sensitivity in adolescent boys (Klingenberg et al. 2013). Schmid et al. (2007) reported a significant decrease in plasma glucagon levels following one night of total sleep deprivation in healthy young men aged 20-40 years. Interestingly, plasma glucagon levels were significantly decreased in the morning following only one night of mild sleep restriction (one night of $4.5 \mathrm{~h}$ of sleep) as compared with levels measured in healthy men allowed to sleep for $7 \mathrm{~h}$ (Schmid et al. 2009). In this study, plasma glucagon levels also remained depressed throughout a $240 \mathrm{~min}$ step-wise hypoglycemic clamp in the sleep restricted group. Sleep deprivation ( $24 \mathrm{~h}$ of continual wakefulness) significantly decreased energy expenditure (resting and postprandial), increased morning plasma glucose (postprandial), and elevated morning levels plasma ghrelin levels, and increased nighttime and daytime levels of cortisol as compared with the control group that was allowed $8 \mathrm{~h}$ of sleep during a normal $24 \mathrm{~h}$ sleep-wake cycle (Benedict et al. 2011). While the mechanisms responsible for these effects remain unknown, they provide compelling evidence to support a linkage among disturbed sleep, dysregulated glucose and energy metabolism, and a predisposition to adverse metabolic consequences.

Experimental animal models have also been utilized to demonstrate that circadian misalignment causes metabolic disturbances. Using a 'night-work' model in rats, Salgado-Delgado et al. (2010) showed that forced activity (and/or food consumption) during the normal rest phase increased body weight, adiposity, and glucose intolerance compared with rats with forced activity in the normal active phase. Furthermore, this experimental protocol disrupted the normal daily rhythms in both clock and metabolic genes and caused hepatic steatosis (Salgado-Delgado et al. 2013). Similarly, dim-light-atnight (dLAN) has been shown to increase weight gain and disrupt circadian rhythms in both the SCN and peripheral tissues (Fonken et al. 2010, 2013a), as well as increase peripheral inflammation when combined with a high-fat diet (Fonken et al. 2013b). Interestingly, re-exposure to a dark night can reverse metabolic disturbances following exposure to dLAN (Fonken et al. 2013c). These data support the hypothesis that activity and/or light in the normal rest (or sleep) phase causes misalignment among different organ systems and intracellular metabolic pathways. Accordingly, circadian misalignment or dyssynchrony may partially explain why night work and shiftwork are strongly associated with obesity and related metabolic diseases. An additional cause of circadian misalignment during shift work is potentially the timing of food intake (as discussed below).

\section{Timing of feeding}

Food consumption is a potent zeitgeber for peripheral circadian clocks, as first demonstrated by Damiola et al. (2000); restricting food access to the sleep-phase shifted circadian clocks in the liver, kidney, and heart, with no effect in the SCN, thereby result in circadian dyssynchrony between central and peripheral clocks. More recently, studies have reported that this experimental protocol differentially influences clocks within metabolically active tissues (e.g. liver, skeletal muscle, and adipose), suggesting that meal feeding also causes dyssynchrony between peripheral clocks (Bray et al. 2013). This is associated with perturbations in metabolic homeostasis, resulting in increased adiposity, decreased glucose tolerance, and dyslipidemia, a metabolic profile often observed in subjects with night-eating syndrome (Stunkard \& Allison 2003, Arble et al. 2009, Bray et al. 2013). Conversely, restricting food intake to the normal activity phase in rodents prevents metabolic disturbances and weight gain associated with high-fat diets (Hatori et al. 2012, Tsai et al. 2013). Evidence also suggests that the timing of macronutrient ingestion within the active/awake period markedly impacts metabolic outcomes. More specifically, consumption of a calorically dense high-fat meal at the end of the active/awake period increases adiposity, decreases glucose tolerance, and increases circulating insulin and leptin levels in mice (relative to consumption of the exact same meal during the beginning of the active period; Bray et al. 2010). This experimental paradigm phase shifts peripheral circadian clocks (ME Young, unpublished observations). Interestingly, when human subjects were forced to consume the majority of their calories immediately before overnight sleep, metabolic perturbations were observed (e.g. dissociation between circulating insulin and glucose levels; Qin et al. 2003). Collectively, these observations suggest that consumption of nutrients at an inappropriate

Published by Bioscientifica Ltd 
time of the day can result in circadian dyssynchrony, associated with metabolic imbalances.

\section{Alcohol consumption}

In addition to high-fat diets, recent studies have reported that other lifestyle factors such as chronic alcohol consumption can alter circadian rhythms in peripheral tissues like gut (Swanson et al. 2011, Forsyth et al. 2013, Summa et al. 2013) and liver (Filiano et al. 2013, Zhou et al. 2014), thus contributing to circadian misalignment and tissue injury. Work from our laboratories revealed that diurnal oscillations in clock genes and CCGs were altered in the liver of ethanol-fed mice exhibiting steatosis (Filiano et al. 2013). Importantly, ethanol feeding induced a phase advance in clock gene expression in liver, but not in SCN, indicating dyssynchrony between the master clock in the SCN and the peripheral clock in the liver. Ethanol consumption also altered the diurnal rhythms in several lipid, carbohydrate, and energy metabolism genes (Filiano et al. 2013), which were confirmed by findings of Zhou et al. (2014). These findings are important because they revealed that chronic alcohol consumption perturbs the circadian clock in the liver and associated downstream metabolic targets. Notably, these results support the hypothesis that ethanol, such as high fat, induces circadian misalignment between molecular oscillators. As a consequence, the peripheral liver clock is no longer in sync with its environment during alcoholic and nonalcoholic fatty liver disease.

\section{Obesity/diabetes}

It is clear that circadian dyssynchrony negatively impacts cardiometabolic parameters. What has also become apparent is that cardiometabolic diseases result in circadian dyssynchrony. For example, Young et al. (2002) reported that circadian clock gene expression was phase shifted in the rat heart following streptozotocin (STZ)-induced diabetes, an effect that has been confirmed for various peripheral clocks (Oishi et al. 2004). Several classic parameters of clock gene expression (e.g. acrophase, amplitude, and mesor) were found to be altered in liver of out-bred male rats treated with STZ or in liver of male spontaneous type 1 diabetes LEW.1AR1-Iddm rats (Hofmann et al. 2013). Specifically, the acrophase of Bmal1 and other clock component genes were phase advanced in liver of STZ-treated rats and Iddm rats, with insulin treatment normalizing some of the dysregulated clock rhythms. Furthermore, peripheral clocks also appear to be phase shifted in rodent models of type 2 diabetes (e.g. $d b / d b$ mice; Kudo et al. 2004). Diet-induced obesity, from unrestricted access to a high-fat diet, altered rhythms in circadian behaviors (activity and feeding), neuropeptides in the hypothalamus, and clock and metabolism gene expression in liver and adipose tissue of mice (Kohsaka et al. 2007). Other studies have reported similar findings in response to diet-induced obesity in highly metabolic tissues (Lizier et al. 2013, Pendergast et al. 2013, Prasai et al. 2013, Shi et al. 2013, Bravo et al. 2014). Recent work by Sassone-Corsi et al. has also shown that a high-fat diet disrupts normal circadian oscillations of the molecular clock and clock-controlled metabolites and transcripts in the liver (Eckel-Mahan et al. 2013); they propose that these high-fat diet-mediated alterations in metabolism are linked to impaired CLOCK-BMAL1 chromatin recruitment and induction of peroxisome proliferator-activated receptor gamma-mediated oscillations in noncyclic genes (EckelMahan etal. 2013). Taken together, these studies support the hypothesis that circadian misalignment consequent to environmental, life-style, and dietary factors most likely contributes to the development of cardiometabolic diseases.

\section{Summary}

Time-of-day-dependent oscillations in metabolic homeostatic parameters are consequent to a complex interplay between exogenous (e.g. behavioral) and endogenous (e.g. circadian clock) influences. Cell autonomous circadian clocks regulate metabolism through a number of direct (e.g. control of enzymes within a distinct metabolic pathway) and indirect (e.g. modulation of sensitivity to endocrine factors) mechanisms (Figs 2 and 3). Furthermore, many clock-controlled metabolic processes 'feedback' on the clock mechanism, such that metabolism should be considered an integral component. In general, the primary function of clock control of processes is to prepare the cell/tissue for a predictable event before its onset; through regulation of metabolism, circadian clocks likely allow anticipation of daily fluctuations in energy demand and/or nutrient availability (e.g. increased physical activity during the awake phase). Common behavioral/ environmental risk factors for cardiometabolic diseases (e.g. food intake, physical activity, lighting, etc.) are known to influence circadian clocks in a tissue-specific manner, leading to the suggestion that circadian misalignment contributes toward obesity, diabetes mellitus, and cardiovascular disease. Accordingly, strategies designed to normalize circadian clock function represent an attractive therapeutic approach for the treatment of cardiometabolic diseases.

Published by Bioscientifica Ltd. 


\section{Declaration of interest}

The authors declare that there is no conflict of interest that could be perceived as prejudicing the impartiality of the review.

\section{Funding}

This work was supported by the National Heart, Lung, and Blood Institute (HL-074259 (M E Y), HL-106199 (M E Y), HL-107709 (M E Y), and HL-92857 $(\mathrm{S} M \mathrm{~B})$ ) and the National Institute on Alcohol Abuse and Alcoholism (AA-18841 (S M B) and AA-20199 (S M B)).

\section{References}

Adamovich Y, Rousso-Noori L, Zwighaft Z, Neufeld-Cohen A, Golik M, Kraut-Cohen J, Wang M, Han X \& Asher G 2014 Circadian clocks and feeding time regulate the oscillations and levels of hepatic triglycerides. Cell Metabolism 19 319-330. (doi:10.1016/j.cmet.2013.12.016)

Alberts P, Johansson BG \& McArthur RA 2006 Characterization of energy expenditure in rodents by indirect calorimetry. Current Protocols in Neuroscience Chapter 9 Unit9.23D.

Alenghat T, Meyers K, Mullican SE, Leitner K, Adeniji-Adele A, Avila J, Bucan M, Ahima RS, Kaestner KH \& Lazar MA 2008 Nuclear receptor corepressor and histone deacetylase 3 govern circadian metabolic physiology. Nature 456 997-1000. (doi:10.1038/nature07541)

Andrews JL, Zhang X, McCarthy JJ, McDearmon EL, Hornberger TA, Russell B, Campbell KS, Arbogast S, Reid MB, Walker JR et al. 2010 CLOCK and BMAL1 regulate MyoD and are necessary for maintenance of skeletal muscle phenotype and function. PNAS 107 19090-19095. (doi:10.1073/pnas.1014523107)

Anea CB, Zhang M, Stepp DW, Simkins GB, Reed G, Fulton DJ \& Rudic RD 2009 Vascular disease in mice with a dysfunctional circadian clock. Circulation 119 1510-1517. (doi:10.1161/CIRCULATIONAHA.108.827477)

Arble DM, Bass J, Laposky AD, Vitaterna MH \& Turek FW 2009 Circadian timing of food intake contributes to weight gain. Obesity 17 2100-2102. (doi:10.1038/oby.2009.264)

Aschoff J 1965 Circadian rhythms in man. Science 148 1427-1432. (doi:10.1126/science.148.3676.1427)

Asher G \& Schibler U 2011 Crosstalk between components of circadian and metabolic cycles in mammals. Cell Metabolism 13 125-137. (doi:10.1016/j.cmet.2011.01.006)

Asher G, Gatfield D, Stratmann M, Reinke H, Dibner C, Kreppel F, Mostoslavsky R, Alt FW \& Schibler U 2008 SIRT1 regulates circadian clock gene expression through PER2 deacetylation. Cell 134 317-328. (doi:10.1016/j.cell.2008.06.050)

Asher G, Reinke H, Altmeyer M, Gutierrez-Arcelus M, Hottiger MO \& Schibler U 2010 Poly(ADP-ribose) polymerase 1 participates in the phase entrainment of circadian clocks to feeding. Cell 142 943-953. (doi:10.1016/j.cell.2010.08.016)

Bahr I, Muhlbauer E, Schucht H \& Peschke E 2011 Melatonin stimulates glucagon secretion in vitro and in vivo. Journal of Pineal Research $\mathbf{5 0}$ 336-344. (doi:10.1111/j.1600-079X.2010.00848.x)

Bannai A \& Tamakoshi A 2014 The association between long working hours and health: a systematic review of epidemiological evidence. Scandinavian Journal of Work, Environment \& Health 40 5-18. (doi:10.5271/sjweh.3388)

Barnea M, Haviv L, Gutman R, Chapnik N, Madar Z \& Froy O 2012 Metformin affects the circadian clock and metabolic rhythms in a tissue-specific manner. Biochimica et Biophysica Acta 1822 1796-1806. (doi:10.1016/j.bbadis.2012.08.005)

Benedict C, Hallschmid M, Lassen A, Mahnke C, Schultes B, Schioth HB, Born J \& Lange T 2011 Acute sleep deprivation reduces energy expenditure in healthy men. American Journal of Clinical Nutrition 93 1229-1236. (doi:10.3945/ajcn.110.006460)
Berson D 2003 Strange vision: ganglion cells as circadian photoreceptors. Trends in Neurosciences 26 314-320. (doi:10.1016/S01662236(03)00130-9)

Bolli GB, De Feo P, De Cosmo S, Perriello G, Ventura MM, Calcinaro F, Lolli C, Campbell P, Brunetti P \& Gerich JE 1984 Demonstration of a dawn phenomenon in normal human volunteers. Diabetes 33 1150-1153. (doi:10.2337/diab.33.12.1150)

Bravo R, Cubero J, Franco L, Mesa M, Galan C, Rodriguez AB, Jarne C \& Barriga C 2014 Body weight gain in rats by a high-fat diet produces chronodisruption in activity/inactivity circadian rhythm. Chronobiology International 31 363-370. (doi:10.3109/07420528.2013.859151)

Bray MS, Shaw CA, Moore MW, Garcia RA, Zanquetta MM, Durgan DJ, Jeong WJ, Tsai JY, Bugger H, Zhang D et al. 2008 Disruption of the circadian clock within the cardiomyocyte influences myocardial contractile function, metabolism, and gene expression. American Journal of Physiology. Heart and Circulatory Physiology 294 H1036-H1047. (doi:10.1152/ajpheart.01291.2007)

Bray MS, Tsai JY, Villegas-Montoya C, Boland BB, Blasier Z, Egbejimi O, Kueht M \& Young ME 2010 Time-of-day-dependent dietary fat consumption influences multiple cardiometabolic syndrome parameters in mice. International Journal of Obesity 34 1589-1598. (doi:10.1038/ijo.2010.63)

Bray MS, Ratcliffe WF, Grenett MH, Brewer RA, Gamble KL \& Young ME 2013 Quantitative analysis of light-phase restricted feeding reveals metabolic dyssynchrony in mice. International Journal of Obesity $\mathbf{3 7}$ 843-852. (doi:10.1038/ijo.2012.137)

Burgueno A, Gemma C, Gianotti TF, Sookoian S \& Pirola CJ 2010 Increased levels of resistin in rotating shift workers: a potential mediator of cardiovascular risk associated with circadian misalignment. Atherosclerosis 210 625-629. (doi:10.1016/j.atherosclerosis.2009.12.032)

Burkeen JF, Womac AD, Earnest DJ \& Zoran MJ 2011 Mitochondrial calcium signaling mediates rhythmic extracellular ATP accumulation in suprachiasmatic nucleus astrocytes. Journal of Neuroscience $\mathbf{3 1}$ 8432-8440. (doi:10.1523/JNEUROSCI.6576-10.2011)

Burris TP 2008 Nuclear hormone receptors for heme: REV-ERB $\alpha$ and REV-ERB $\beta$ are ligand-regulated components of the mammalian clock. Molecular Endocrinology 22 1509-1520. (doi:10.1210/me.2007-0519)

Buxton OM, Cain SW, O'Connor SP, Porter JH, Duffy JF, Wang W, Czeisler CA \& Shea SA 2012 Adverse metabolic consequences in humans of prolonged sleep restriction combined with circadian disruption. Science Translational Medicine 4 129ra143. (doi:10.1126/scitranslmed.3003200)

Calvo JA, Daniels TG, Wang X, Paul A, Lin J, Spiegelman BM, Stevenson SC \& Rangwala SM 2008 Muscle-specific expression of PPAR $\gamma$ coactivator- $1 \alpha$ improves exercise performance and increases peak oxygen uptake. Journal of Applied Physiology 104 1304-1312. (doi:10.1152/japplphysiol. 01231.2007)

Cardone L, Hirayama J, Giordano F, Tamaru T, Palvimo JJ \& Sassone-Corsi P 2005 Circadian clock control by SUMOylation of BMAL1. Science $\mathbf{3 0 9}$ 1390-1394. (doi:10.1126/science.1110689)

Carroll KF \& Nestel PJ 1973 Diurnal variation in glucose tolerance and in insulin secretion in man. Diabetes 22 333-348.

Carvas JM, Vukolic A, Yepuri G, Xiong Y, Popp K, Schmutz I, Chappuis S, Albrecht U, Ming XF, Montani JP et al. 2012 Period2 gene mutant mice show compromised insulin-mediated endothelial nitric oxide release and altered glucose homeostasis. Frontiers in Physiology 3337. (doi:10.3389/fphys.2012.00337)

Chen JD, Lin YC \& Hsiao ST 2010 Obesity and high blood pressure of 12-hour night shift female clean-room workers. Chronobiology International 27 334-344. (doi:10.3109/07420520903502242)

Clougherty JE, Souza K \& Cullen MR 2010 Work and its role in shaping the social gradient in health. Annals of the New York Academy of Sciences 1186 102-124. (doi:10.1111/j.1749-6632.2009.05338.x)

Coomans CP, van den Berg SA, Lucassen EA, Houben T, Pronk AC, van der Spek RD, Kalsbeek A, Biermasz NR, Willems van Dijk K, Romijn JA et al. 2013 The suprachiasmatic nucleus controls circadian energy metabolism and hepatic insulin sensitivity. Diabetes 62 1102-1108. (doi:10.2337/db12-0507) 
Copertaro A, Bracci M, Barbaresi M \& Santarelli L 2008 Assessment of cardiovascular risk in shift healthcare workers. European Journal of Cardiovascular Prevention and Rehabilitation 15 224-229. (doi:10.1097/ HJR.0b013e3282f364c0)

Dallmann R, Viola AU, Tarokh L, Cajochen C \& Brown SA 2012 The human circadian metabolome. PNAS 109 2625-2629. (doi:10.1073/pnas. 1114410109)

Damiola F, Le Minh N, Preitner N, Kornmann B, Fleury-Olela F \& Schibler U 2000 Restricted feeding uncouples circadian oscillators in peripheral tissues from the central pacemaker in the suprachiasmatic nucleus. Genes and Development 14 2950-2961. (doi:10.1101/gad.183500)

De Bacquer D, Van Risseghem M, Clays E, Kittel F, De Backer G \& Braeckman L 2009 Rotating shift work and the metabolic syndrome: a prospective study. International Journal of Epidemiology 38 848-854. (doi:10.1093/ije/dyn360)

Dioum EM, Rutter J, Tuckerman JR, Gonzalez G, Gilles-Gonzalez MA \& McKnight SL 2002 NPAS2: a gas-responsive transcription factor. Science 298 2385-2387. (doi:10.1126/science.1078456)

Doi M, Hirayama J \& Sassone-Corsi P 2006 Circadian regulator CLOCK is a histone acetyltransferase. Cell 125 497-508. (doi:10.1016/j.cell.2006. 03.033)

Doi R, Oishi K \& Ishida N 2010 CLOCK regulates circadian rhythms of hepatic glycogen synthesis through transcriptional activation of Gys2. Journal of Biological Chemistry 285 22114-22121. (doi:10.1074/jbc. M110.110361)

Douris N, Kojima S, Pan X, Lerch-Gaggl AF, Duong SQ, Hussain MM \& Green CB 2011 Nocturnin regulates circadian trafficking of dietary lipid in intestinal enterocytes. Current Biology 21 1347-1355. (doi:10.1016/j.cub.2011.07.018)

Duez H \& Staels B 2009 Rev-erb- $\alpha$ : an integrator of circadian rhythms and metabolism. Journal of Applied Physiology 107 1972-1980. (doi:10.1152/ japplphysiol.00570.2009)

Duffield GE, Best JD, Meurers BH, Bittner A, Loros JJ \& Dunlap JC 2002 Circadian programs of transcriptional activation, signaling, and protein turnover revealed by microarray analysis of mammalian cells. Current Biology 12 551-557. (doi:10.1016/S0960-9822(02)00765-0)

Durgan D, Pulinilkunnil T, Villegas-Montoya C, Garvey M, Frangogiannis N, Michael L, Chow C, Dyck J \& Young M 2010 Short communication: Ischemia/reperfusion tolerance is time-of-day-dependent: mediation by the cardiomyocyte circadian clock. Circulation Research 106 546-550. (doi:10.1161/CIRCRESAHA.109.209346)

Durgan DJ, Pat BM, Laczy B, Bradley JA, Tsai JY, Grenett MH, Ratcliffe WF, Brewer RA, Nagendran J, Villegas-Montoya C et al. 2011 O-GlcNAcylation, novel post-translational modification linking myocardial metabolism and cardiomyocyte circadian clock. Journal of Biological Chemistry 286 44606-44619. (doi:10.1074/jbc.M111.278903)

Dyar KA, Ciciliot S, Wright LE, Bienso RS, Tagliazucchi GM, Patel VR, Forcato M, Paz MI, Gudiksen A, Solagna F et al. 2014 Muscle insulin sensitivity and glucose metabolism are controlled by the intrinsic muscle clock. Molecular Metabolism 3 29-41. (doi:10.1016/j.molmet.2013.10.005)

Eckel-Mahan KL, Patel VR, de Mateo S, Orozco-Solis R, Ceglia NJ, Sahar S, Dilag-Penilla SA, Dyar KA, Baldi P \& Sassone-Corsi P 2013 Reprogramming of the circadian clock by nutritional challenge. Cell $\mathbf{1 5 5}$ 1464-1478. (doi:10.1016/j.cell.2013.11.034)

Edery I 2000 Circadian rhythms in a nutshell. Physiological Genomics 3 59-74. Edgar RS, Green EW, Zhao Y, van Ooijen G, Olmedo M, Qin X, Xu Y, Pan M, Valekunja UK, Feeney KA et al. 2012 Peroxiredoxins are conserved markers of circadian rhythms. Nature 485 459-464. (doi:10.1038/ nature11088)

Esquirol Y, Perret B, Ruidavets JB, Marquie JC, Dienne E, Niezborala M \& Ferrieres J 2011 Shift work and cardiovascular risk factors: new knowledge from the past decade. Archives of Cardiovascular Diseases 104 636-668. (doi:10.1016/j.acvd.2011.09.004)

Fernstrom JD, Wurtman RJ, Hammarstrom-Wiklund B, Rand WM, Munro HN \& Davidson CS 1979 Diurnal variations in plasma concentrations of tryptophan, tyrosine, and other neutral amino acids: effect of dietary protein intake. American Journal of Clinical Nutrition 32 1912-1922.
Filiano AN, Millender-Swain T, Johnson R Jr, Young ME, Gamble KL \& Bailey SM 2013 Chronic ethanol consumption disrupts the core molecular clock and diurnal rhythms of metabolic genes in the liver without affecting the suprachiasmatic nucleus. PLOS ONE 8 e71684. (doi:10.1371/journal.pone.0071684)

la Fleur SE, Kalsbeek A, Wortel J, Fekkes ML \& Buijs RM 2001 A daily rhythm in glucose tolerance: a role for the suprachiasmatic nucleus. Diabetes $\mathbf{5 0}$ 1237-1243. (doi:10.2337/diabetes.50.6.1237)

Fonken LK, Workman JL, Walton JC, Weil ZM, Morris JS, Haim A \& Nelson RJ 2010 Light at night increases body mass by shifting the time of food intake. PNAS 107 18664-18669. (doi:10.1073/pnas.1008734107)

Fonken LK, Aubrecht TG, Melendez-Fernandez OH, Weil ZM \& Nelson RJ $2013 a$ Dim light at night disrupts molecular circadian rhythms and increases body weight. Journal of Biological Rhythms 28 262-271. (doi:10.1177/0748730413493862)

Fonken LK, Lieberman RA, Weil ZM \& Nelson RJ 2013b Dim light at night exaggerates weight gain and inflammation associated with a high-fat diet in male mice. Endocrinology 154 3817-3825. (doi:10.1210/ en.2013-1121)

Fonken LK, Weil ZM \& Nelson RJ 2013c Dark nights reverse metabolic disruption caused by dim light at night. Obesity 21 1159-1164. (doi:10.1002/oby.20108)

Forsyth CB, Voigt RM, Shaikh M, Tang Y, Cederbaum AI, Turek FW \& Keshavarzian A 2013 Role for intestinal Cyp2e1 in alcohol-induced circadian gene-mediated intestinal hyperpermeability. American Journal of Physiology. Gastrointestinal and Liver Physiology $\mathbf{3 0 5}$ G189-G195. (doi:10.1152/ajpgi.00354.2012)

Fulks RM, Li JB \& Goldberg AL 1975 Effects of insulin, glucose, and amino acids on protein turnover in rat diaphragm. Journal of Biological Chemistry 250 290-298.

Gagliardino JJ, Pessacq MT, Hernandez RE \& Rebolledo OR 1978 Circadian variations in serum glucagon and hepatic glycogen and cyclic AMP concentrations. Journal of Endocrinology 78 297-298. (doi:10.1677/ joe.0.0780297)

Garlick PJ, Millward DJ \& James WP 1973 The diurnal response of muscle and liver protein synthesis in vivo in meal-fed rats. Biochemical Journal 136 935-945.

Gekakis N, Staknis D, Nguyen H, Davis F, Wilsbacher L, King D, Takahashi J \& Weitz C 1998 Role of the CLOCK protein in the mammalian circadian mechanism. Science 280 1564-1569. (doi:10.1126/science.280.5369.1564)

Gerhart-Hines Z, Feng D, Emmett MJ, Everett LJ, Loro E, Briggs ER, Bugge A, Hou C, Ferrara C, Seale P et al. 2013 The nuclear receptor Rev-erb $\alpha$ controls circadian thermogenic plasticity. Nature $\mathbf{5 0 3} 410-413$. (doi:10.1038/nature12642)

Gibson T, Stimmler L, Jarrett RJ, Rutland P \& Shiu M 1975 Diurnal variation in the effects of insulin on blood glucose, plasma non-esterified fatty acids and growth hormone. Diabetologia 11 83-88. (doi:10.1007/ BF00422823)

Goldstein JL, DeBose-Boyd RA \& Brown MS 2006 Protein sensors for membrane sterols. Cell 124 35-46. (doi:10.1016/j.cell.2005.12.022)

Gupta N \& Ragsdale SW 2011 Thiol-disulfide redox dependence of heme binding and heme ligand switching in nuclear hormone receptor rev-erb $\{\beta\}$. Journal of Biological Chemistry 286 4392-4403. (doi:10.1074/ jbc.M110.193466)

Handschin C, Lin J, Rhee J, Peyer AK, Chin S, Wu PH, Meyer UA \& Spiegelman BM 2005 Nutritional regulation of hepatic heme biosynthesis and porphyria through PGC-1 $\alpha$. Cell 122 505-515. (doi:10.1016/j.cell.2005.06.040)

Hardin PE \& Yu W 2006 Circadian transcription: passing the HAT to CLOCK. Cell 125 424-426. (doi:10.1016/j.cell.2006.04.010)

Harms E, Kivimae S, Young MW \& Saez L 2004 Posttranscriptional and posttranslational regulation of clock genes. Journal of Biological Rhythms 19 361-373. (doi:10.1177/0748730404268111)

Hart GW, Slawson C, Ramirez-Correa G \& Lagerlof O 2011 Cross talk between $O-G l c N A c y l a t i o n$ and phosphorylation: roles in signaling, http://joe.endocrinology-journals.org DOI: 10.1530/JOE-14-0200
() 2014 Society for Endocrinology Printed in Great Britain 
transcription, and chronic disease. Annual Review of Biochemistry $\mathbf{8 0}$ 825-858. (doi:10.1146/annurev-biochem-060608-102511)

Hatori M, Vollmers C, Zarrinpar A, DiTacchio L, Bushong EA, Gill S, Leblanc M, Chaix A, Joens M, Fitzpatrick JA et al. 2012 Time-restricted feeding without reducing caloric intake prevents metabolic diseases in mice fed a high-fat diet. Cell Metabolism 15 848-860. (doi:10.1016/j. cmet.2012.04.019)

Hirota T \& Fukada Y 2004 Resetting mechanism of central and peripheral circadian clocks in mammals. Zoological Science 21 359-368. (doi:10. 2108/zsj.21.359)

Hofmann K, Schonerstedt U, Muhlbauer E, Wedekind D \& Peschke E 2013 Clock gene expression in the liver of streptozotocin-induced and spontaneous type 1 diabetic rats. Hormone and Metabolic Research 45 629-639. (doi:10.1055/s-0033-1343462)

Hogenesch J, Gu Y, Jain S \& Bradfield C 1998 The basic-helix-loop-helixPAS orphan MOP3 forms transcriptionally active complexes with circadian and hypoxia factors. PNAS 95 5474-5479. (doi:10.1073/pnas. 95.10.5474)

Honma S, Kawamoto T, Takagi Y, Fujimoto K, Sato F, Noshiro M, Kato Y \& Honma K 2002 Dec1 and Dec2 are regulators of the mammalian molecular clock. Nature 419 841-844. (doi:10.1038/nature01123)

Hoogerwerf WA, Hellmich HL, Cornelissen G, Halberg F, Shahinian VB, Bostwick J, Savidge TC \& Cassone VM 2007 Clock gene expression in the murine gastrointestinal tract: endogenous rhythmicity and effects of a feeding regimen. Gastroenterology 133 1250-1260. (doi:10.1053/j. gastro.2007.07.009)

Imai S 2010 "Clocks" in the NAD World: NAD as a metabolic oscillator for the regulation of metabolism and aging. Biochimica et Biophysica Acta 1804 1584-1590. (doi:10.1016/j.bbapap.2009.10.024)

Imai S, Armstrong CM, Kaeberlein M \& Guarente L 2000 Transcriptional silencing and longevity protein Sir2 is an NAD-dependent histone deacetylase. Nature 403 795-800. (doi:10.1038/35001622)

Ishikawa K \& Shimazu T 1976 Daily rhythms of glycogen synthetase and phosphorylase activities in rat liver: influence of food and light. Life Sciences 19 1873-1878. (doi:10.1016/0024-3205(76)90119-3)

Ishikawa K \& Shimazu T 1980 Circadian rhythm of liver glycogen metabolism in rats: effects of hypothalamic lesions. American Journal of Physiology 238 E21-E25.

Isobe Y, Hida H \& Nishino H 2011 Circadian rhythm of metabolic oscillation in suprachiasmatic nucleus depends on the mitochondrial oxidation state, reflected by cytochrome $C$ oxidase and lactate dehydrogenase. Journal of Neuroscience Research 89 929-935. (doi:10.1002/jnr.22609)

Jordan SD \& Lamia KA 2013 AMPK at the crossroads of circadian clocks and metabolism. Molecular and Cellular Endocrinology 366 163-169. (doi:10. 1016/j.mce.2012.06.017)

Kaasik K \& Lee CC 2004 Reciprocal regulation of haem biosynthesis and the circadian clock in mammals. Nature 430 467-471. (doi:10.1038/ nature02724)

Kaasik K, Kivimae S, Allen JJ, Chalkley RJ, Huang Y, Baer K, Kissel H, Burlingame AL, Shokat KM, Ptacek LJ et al. 2013 Glucose sensor OGlcNAcylation coordinates with phosphorylation to regulate circadian clock. Cell Metabolism 17 291-302. (doi:10.1016/j.cmet.2012.12.017)

Kalsbeek A \& Strubbe JH 1998 Circadian control of insulin secretion is independent of the temporal distribution of feeding. Physiology \& Behavior 63 553-558. (doi:10.1016/S0031-9384(97)00493-9)

Kalsbeek A, la Fleur SE \& Fliers E 2014 Circadian control of glucose metabolism. Molecular Medicine 3 372-383. (doi:10.1016/j.molmet. 2014.03.002)

Karlsson B, Knutsson A \& Lindahl B 2001 Is there an association between shift work and having a metabolic syndrome? Results from a population based study of 27,485 people Occupational and Environmental Medicine 58 747-752. (doi:10.1136/oem.58.11.747)

Kida K, Nishio T, Yokozawa T, Nagai K, Matsuda H \& Nakagawa H 1980 The circadian change of gluconeogenesis in the liver in vivo in fed rats. Journal of Biochemistry 88 1009-1013.
Kim EY, Jeong EH, Park S, Jeong HJ, Edery I \& Cho JW 2012 A role for $O$-GlcNAcylation in setting circadian clock speed. Genes and Development 26 490-502. (doi:10.1101/gad.182378.111)

Klingenberg L, Chaput JP, Holmback U, Visby T, Jennum P, Nikolic M, Astrup A \& Sjodin A 2013 Acute sleep restriction reduces insulin sensitivity in adolescent boys. Sleep 36 1085-1090. (doi:10.5665/ sleep.2816)

Kloss B, Price J, Saez L, Blau J, Rothenfluh A, Wesley C \& Young M 1998 The Drosophila clock gene double-time encodes a protein closely related to human casein kinase Ic. Cell 94 97-107. (doi:10.1016/S00928674(00)81225-8)

Knutsson A 2003 Health disorders of shift workers. Occupational Medicine $\mathbf{5 3}$ 103-108. (doi:10.1093/occmed/kqg048)

Kohsaka A, Laposky AD, Ramsey KM, Estrada C, Joshu C, Kobayashi Y, Turek FW \& Bass J 2007 High-fat diet disrupts behavioral and molecular circadian rhythms in mice. Cell Metabolism 6 414-421. (doi:10.1016/ j.cmet.2007.09.006)

Kornmann B, Schaad O, Bujard H, Takahashi JS \& Schibler U 2007 Systemdriven and oscillator-dependent circadian transcription in mice with a conditionally active liver clock. PLoS Biology 5 e34. (doi:10.1371/ journal.pbio.0050034)

Kraus WL \& Hottiger MO 2013 PARP-1 and gene regulation: progress and puzzles. Molecular Aspects of Medicine 34 1109-1123. (doi:10.1016/ j.mam.2013.01.005)

Kroenke CH, Spiegelman D, Manson J, Schernhammer ES, Colditz GA \& Kawachi I 2007 Work characteristics and incidence of type 2 diabetes in women. American Journal of Epidemiology 165 175-183. (doi:10.1093/ aje/kwj355)

Kudo T, Akiyama M, Kuriyama K, Sudo M, Moriya T \& Shibata S 2004 Night-time restricted feeding normalises clock genes and Pai-1 gene expression in the db/db mouse liver. Diabetologia 47 1425-1436. (doi:10.1007/s00125-004-1461-0)

La Fleur SE, Kalsbeek A, Wortel J \& Buijs RM 1999 A suprachiasmatic nucleus generated rhythm in basal glucose concentrations. Journal of Neuroendocrinology 11 643-652. (doi:10.1046/j.1365-2826. 1999.00373.x)

Lamia KA, Storch KF \& Weitz CJ 2008 Physiological significance of a peripheral tissue circadian clock. PNAS 105 15172-15177. (doi:10.1073/pnas.0806717105)

Lamia KA, Sachdeva UM, DiTacchio L, Williams EC, Alvarez JG, Egan DF, Vasquez DS, Juguilon H, Panda S, Shaw RJ et al. 2009 AMPK regulates the circadian clock by cryptochrome phosphorylation and degradation. Science 326 437-440. (doi:10.1126/science.1172156)

Lan F, Cacicedo JM, Ruderman N \& Ido Y 2008 SIRT1 modulation of the acetylation status, cytosolic localization, and activity of LKB1. Possible role in AMP-activated protein kinase activation. Journal of Biological Chemistry 283 27628-27635. (doi:10.1074/jbc.M805711200)

Landry J, Slama JT \& Sternglanz R 2000 Role of NAD(+) in the deacetylase activity of the SIR2-like proteins. Biochemical and Biophysical Research Communications 278 685-690. (doi:10.1006/bbrc.2000.3854)

Langmesser S \& Albrecht U 2006 Life time-circadian clocks, mitochondria and metabolism. Chronobiology International 23 151-157. (doi:10.1080/ 07420520500464437)

Lee A, Ader M, Bray GA \& Bergman RN 1992 Diurnal variation in glucose tolerance. Cyclic suppression of insulin action and insulin secretion in normal-weight, but not obese, subjects. Diabetes 41 750-759. (doi:10.2337/diab.41.6.750)

Lee C, Etchegaray JP, Cagampang FR, Loudon AS \& Reppert SM 2001 Posttranslational mechanisms regulate the mammalian circadian clock. Cell 107 855-867. (doi:10.1016/S0092-8674(01)00610-9)

Lee J, Kim MS, Li R, Liu VY, Fu L, Moore DD, Ma K \& Yechoor VK 2011 Loss of Bmal1 leads to uncoupling and impaired glucose-stimulated insulin secretion in $\beta$-cells. Islets 3 381-388. (doi:10.4161/isl.3.6.18157)

Leighton B, Kowalchuk JM, Challiss RA \& Newsholme EA 1988 Circadian rhythm in sensitivity of glucose metabolism to insulin in rat soleus muscle. American Journal of Physiology 255 E41-E45. 
Le Martelot G, Claudel T, Gatfield D, Schaad O, Kornmann B, Lo Sasso G, Moschetta A \& Schibler U 2009 REV-ERB $\alpha$ participates in circadian SREBP signaling and bile acid homeostasis. PLoS Biology $\mathbf{7}$ e1000181. (doi:10.1371/journal.pbio.1000181)

Leproult R, Holmback U \& Van Cauter E 2014 Circadian misalignment augments markers of insulin resistance and inflammation, independently of sleep loss. Diabetes 63 1860-1869. (doi:10.2337/db13-1546)

Li MD, Ruan HB, Hughes ME, Lee JS, Singh JP, Jones SP, Nitabach MN \& Yang X 2013 O-GlcNAc signaling entrains the circadian clock by inhibiting BMAL1/CLOCK ubiquitination. Cell Metabolism 17 303-310. (doi:10.1016/j.cmet.2012.12.015)

Lin JD 2009 Minireview: The PGC-1 coactivator networks: chromatinremodeling and mitochondrial energy metabolism. Molecular Endocrinology 23 2-10. (doi:10.1210/me.2008-0344)

Lin YC, Hsiao TJ \& Chen PC 2009 Persistent rotating shift-work exposure accelerates development of metabolic syndrome among middle-aged female employees: a five-year follow-up. Chronobiology International 26 740-755. (doi:10.1080/07420520902929029)

Lipsky NG \& Pedersen PL 1981 Mitochondrial turnover in animal cells. Half-lives of mitochondria and mitochondrial subfractions of rat liver based on $\left[{ }^{14} \mathrm{C}\right]$ bicarbonate incorporation. Journal of Biological Chemistry 256 8652-8657.

Liu C, Li S, Liu T, Borjigin J \& Lin JD 2007 Transcriptional coactivator PGC$1 \alpha$ integrates the mammalian clock and energy metabolism. Nature $\mathbf{4 4 7}$ 477-481. (doi:10.1038/nature05767)

Lizier M, Bomba L, Minuti A, Chegdani F, Capraro J, Tondelli B, Mazza R, Callegari ML, Trevisi E, Rossi F et al. 2013 The nutrigenomic investigation of C57BL/6N mice fed a short-term high-fat diet highlights early changes in clock genes expression. Genes \& Nutrition $\mathbf{8}$ 465-474. (doi:10.1007/s12263-013-0344-8)

Lucassen EA, Rother KI \& Cizza G 2012 Interacting epidemics? Sleep curtailment, insulin resistance, and obesity Annals of the New York Academy of Sciences 1264 110-134. (doi:10.1111/j.1749-6632.2012.06655.x)

Lund J, Arendt J, Hampton SM, English J \& Morgan LM 2001 Postprandial hormone and metabolic responses amongst shift workers in Antarctica. Journal of Endocrinology 171 557-564. (doi:10.1677/joe.0.1710557)

Malloy JN, Paulose JK, Li Y \& Cassone VM 2012 Circadian rhythms of gastrointestinal function are regulated by both central and peripheral oscillators. American Journal of Physiology. Gastrointestinal and Liver Physiology 303 G461-G473. (doi:10.1152/ajpgi.00369.2011)

Marcheva B, Ramsey KM, Buhr ED, Kobayashi Y, Su H, Ko CH, Ivanova G, Omura C, Mo S, Vitaterna MH et al. 2010 Disruption of the clock components CLOCK and BMAL1 leads to hypoinsulinaemia and diabetes. Nature 466 627-631. (doi:10.1038/nature09253)

Masri S, Patel VR, Eckel-Mahan KL, Peleg S, Forne I, Ladurner AG, Baldi P, Imhof A \& Sassone-Corsi P 2013 Circadian acetylome reveals regulation of mitochondrial metabolic pathways. PNAS 110 3339-3344. (doi:10.1073/pnas.1217632110)

McCarthy JJ, Andrews JL, McDearmon EL, Campbell KS, Barber BK, Miller BH, Walker JR, Hogenesch JB, Takahashi JS \& Esser KA 2007 Identification of the circadian transcriptome in adult mouse skeletal muscle. Physiological Genomics 31 86-95. (doi:10.1152/physiolgenomics.00066.2007)

Millar AJ 2000 Clock proteins: turned over after hours? Current Biology 10 R529-R531. (doi:10.1016/S0960-9822(00)00586-8)

Miwa S, Lawless C \& von Zglinicki T 2008 Mitochondrial turnover in liver is fast in vivo and is accelerated by dietary restriction: application of a simple dynamic model. Aging Cell 7 920-923. (doi:10.1111/j.14749726.2008.00426.x)

Miyamoto Y \& Sancar A 1998 Vitamin B2-based blue-light photoreceptors in the retinohypothalamic tract as the photoactive pigments for setting the circadian clock in mammals. PNAS 95 6097-6102. (doi:10.1073/ pnas.95.11.6097)

Molusky MM, Li S, Ma D, Yu L \& Lin JD 2012 Ubiquitin-specific protease 2 regulates hepatic gluconeogenesis and diurnal glucose metabolism through 11ß-hydroxysteroid dehydrogenase 1. Diabetes 61 1025-1035. (doi:10.2337/db11-0970)
Morikawa Y, Nakagawa H, Miura K, Soyama Y, Ishizaki M, Kido T, Naruse Y, Suwazono Y \& Nogawa K 2005 Shift work and the risk of diabetes mellitus among Japanese male factory workers. Scandinavian Journal of Work, Environment \& Health 31 179-183. (doi:10.5271/sjweh.867)

Muhlbauer E, Gross E, Labucay K, Wolgast S \& Peschke E 2009 Loss of melatonin signalling and its impact on circadian rhythms in mouse organs regulating blood glucose. European Journal of Pharmacology $\mathbf{6 0 6}$ 61-71. (doi:10.1016/j.ejphar.2009.01.029)

Mukherji A, Kobiita A, Ye T \& Chambon P 2013 Homeostasis in intestinal epithelium is orchestrated by the circadian clock and microbiota cues transduced by TLRs. Cell 153 812-827. (doi:10.1016/j.cell.2013.04.020)

Nagaya T, Yoshida H, Takahashi H \& Kawai M 2002 Markers of insulin resistance in day and shift workers aged 30-59 years. International Archives of Occupational and Environmental Health 75 562-568. (doi:10.1007/s00420-002-0370-0)

Nakahata Y, Kaluzova M, Grimaldi B, Sahar S, Hirayama J, Chen D, Guarente LP \& Sassone-Corsi P 2008 The $\mathrm{NAD}^{+}$-dependent deacetylase SIRT1 modulates CLOCK-mediated chromatin remodeling and circadian control. Cell 134 329-340. (doi:10.1016/j.cell.2008.07.002)

Nakahata Y, Sahar S, Astarita G, Kaluzova M \& Sassone-Corsi P 2009 Circadian control of the $\mathrm{NAD}^{+}$salvage pathway by CLOCK-SIRT1. Science 324 654-657. (doi:10.1126/science.1170803)

Nikiforov A, Dolle C, Niere M \& Ziegler M 2011 Pathways and subcellular compartmentation of NAD biosynthesis in human cells: from entry of extracellular precursors to mitochondrial NAD generation. Journal of Biological Chemistry 286 21767-21778. (doi:10.1074/ jbc.M110.213298)

Nikonova EV, Vijayasarathy C, Zhang L, Cater JR, Galante RJ, Ward SE, Avadhani NG \& Pack AI 2005 Differences in activity of cytochrome $C$ oxidase in brain between sleep and wakefulness. Sleep 28 21-27.

Oishi K, Kasamatsu M \& Ishida N 2004 Gene- and tissue-specific alterations of circadian clock gene expression in streptozotocin-induced diabetic mice under restricted feeding. Biochemical and Biophysical Research Communications 317 330-334. (doi:10.1016/j.bbrc.2004.03.055)

Pan X \& Hussain MM 2007 Diurnal regulation of microsomal triglyceride transfer protein and plasma lipid levels. Journal of Biological Chemistry 282 24707-24719. (doi:10.1074/jbc.M701305200)

Pan X \& Hussain MM 2009 Clock is important for food and circadian regulation of macronutrient absorption in mice. Journal of Lipid Research 50 1800-1813. (doi:10.1194/jlr.M900085-JLR200)

Pan X, Zhang Y, Wang L \& Hussain MM 2010 Diurnal regulation of MTP and plasma triglyceride by CLOCK is mediated by SHP. Cell Metabolism 12 174-186. (doi:10.1016/j.cmet.2010.05.014)

Panda S, Antoch MP, Miller BH, Su AI, Schook AB, Straume M, Schultz PG, Kay SA, Takahashi JS \& Hogenesch JB 2002 Coordinated transcription of key pathways in the mouse by the circadian clock. Cell 109 307-320. (doi:10.1016/S0092-8674(02)00722-5)

Pardee KI, Xu X, Reinking J, Schuetz A, Dong A, Liu S, Zhang R, Tiefenbach J, Lajoie G, Plotnikov AN et al. 2009 The structural basis of gas-responsive transcription by the human nuclear hormone receptor REV-ERB $\beta$. PLoS Biology 7 e43. (doi:10.1371/journal.pbio.1000043)

Pardini L, Kaeffer B, Trubuil A, Bourreille A \& Galmiche JP 2005 Human intestinal circadian clock: expression of clock genes in colonocytes lining the crypt. Chronobiology International 22 951-961. (doi:10.1080/ 07420520500395011)

Peek CB, Ramsey KM, Marcheva B \& Bass J 2012 Nutrient sensing and the circadian clock. Trends in Endocrinology and Metabolism 23 312-318. (doi:10.1016/j.tem.2012.02.003)

Peek CB, Affinati AH, Ramsey KM, Kuo H-Y, Yu W, Sena LA, Ilkayeva O, Marcheva B, Kobayashi Y, Omura C et al. 2013 Circadian clock NAD ${ }^{+}$ cycle drives mitochondrial oxidative metabolism in mice. Science $\mathbf{3 4 2}$ 1243417. (doi:10.1126/science.1243417)

Pendergast JS, Branecky KL, Yang W, Ellacott KL, Niswender KD \& Yamazaki S 2013 High-fat diet acutely affects circadian organisation and eating behavior. European Journal of Neuroscience 37 1350-1356. (doi:10.1111/ejn.12133)

Published by Bioscientifica Ltd. 
Peret J, Chanez M \& Pascal G 1976 Schedule of protein ingestion and circadian rhythm of certain hepatic enzyme activities involved in glucose metabolism in the rat. Nutrition and Metabolism 20 143-157. (doi:10.1159/000175698)

Peschke E \& Peschke D 1998 Evidence for a circadian rhythm of insulin release from perifused rat pancreatic islets. Diabetologia 41 1085-1092. (doi:10.1007/s001250051034)

Pittendrigh C \& Daan S 1976 A functional analysis of circadian pacemakers in nocturnal rodents. Journal of Comparative Physiology 106 333-355. (doi:10.1007/BF01417860)

Pizarro A, Hayer K, Lahens NF \& Hogenesch JB 2013 CircaDB: a database of mammalian circadian gene expression profiles. Nucleic Acids Research 41 D1009-D1013. (doi:10.1093/nar/gks1161)

Polidarova L, Sladek M, Sotak M, Pacha J \& Sumova A 2011 Hepatic, duodenal, and colonic circadian clocks differ in their persistence under conditions of constant light and in their entrainment by restricted feeding. Chronobiology International 28 204-215. (doi:10.3109/ 07420528.2010.548615)

Prasai MJ, Mughal RS, Wheatcroft SB, Kearney MT, Grant PJ \& Scott EM 2013 Diurnal variation in vascular and metabolic function in dietinduced obesity: divergence of insulin resistance and loss of clock rhythm. Diabetes 62 1981-1989. (doi:10.2337/db11-1740)

Preitner N, Damiola F, Lopez-Molina L, Zakany J, Duboule D, Albrecht U \& Schibler U 2002 The orphan nuclear receptor REV-ERB $\alpha$ controls circadian transcription within the positive limb of the mammalian circadian oscillator. Cell 110 251-260. (doi:10.1016/S00928674(02)00825-5)

Qin LQ, Li J, Wang Y, Wang J, Xu JY \& Kaneko T 2003 The effects of nocturnal life on endocrine circadian patterns in healthy adults. Life Sciences 73 2467-2475. (doi:10.1016/S0024-3205(03)00628-3)

Raghuram S, Stayrook KR, Huang P, Rogers PM, Nosie AK, McClure DB, Burris LL, Khorasanizadeh S, Burris TP \& Rastinejad F 2007 Identification of heme as the ligand for the orphan nuclear receptors REV-ERB $\alpha$ and REV-ERB $\beta$. Nature Structural \& Molecular Biology 14 1207-1213. (doi:10.1038/nsmb1344)

Ramsey KM, Yoshino J, Brace CS, Abrassart D, Kobayashi Y, Marcheva B, Hong HK, Chong JL, Buhr ED, Lee C et al. 2009 Circadian clock feedback cycle through NAMPT-mediated NAD ${ }^{+}$biosynthesis. Science 324 651-654. (doi:10.1126/science.1171641)

Rannels DE, Kao R \& Morgan HE 1975 Effect of insulin on protein turnover in heart muscle. Journal of Biological Chemistry 250 1694-1701.

Rau E \& Meyer DK 1975 A diurnal rhythm of incorporation of L-[3H] leucine in myocardium of the rat. Recent Advances in Studies on Cardiac Structure and Metabolism 7 105-110.

Reddy AB, Karp NA, Maywood ES, Sage EA, Deery M, O'Neill JS, Wong GK, Chesham J, Odell M, Lilley KS et al. 2006 Circadian orchestration of the hepatic proteome. Current Biology 16 1107-1115. (doi:10.1016/j.cub. 2006.04.026)

Rogers PM, Ying L \& Burris TP 2008 Relationship between circadian oscillations of Rev-erb $\alpha$ expression and intracellular levels of its ligand, heme. Biochemical and Biophysical Research Communications 368 955-958. (doi:10.1016/j.bbrc.2008.02.031)

Rose AJ \& Richter EA 2005 Skeletal muscle glucose uptake during exercise: how is it regulated? Physiology 20 260-270. (doi:10.1152/physiol.00012.2005)

Rudic RD, McNamara P, Curtis AM, Boston RC, Panda S, Hogenesch JB \& Fitzgerald GA 2004 BMAL1 and CLOCK, two essential components of the circadian clock, are involved in glucose homeostasis. PLoS Biology 2 e377. (doi:10.1371/journal.pbio.0020377)

Ruiter M, La Fleur SE, van Heijningen C, van der Vliet J, Kalsbeek A \& Buijs RM 2003 The daily rhythm in plasma glucagon concentrations in the rat is modulated by the biological clock and by feeding behavior. Diabetes $\mathbf{5 2}$ 1709-1715. (doi:10.2337/diabetes.52.7.1709)

Rutter J, Reick M, Wu LC \& McKnight SL 2001 Regulation of clock and NPAS2 DNA binding by the redox state of NAD cofactors. Science 293 510-514. (doi:10.1126/science.1060698)
Sahar S \& Sassone-Corsi P 2012 Regulation of metabolism: the circadian clock dictates the time. Trends in Endocrinology and Metabolism 23 1-8. (doi:10.1016/j.tem.2011.10.005)

Sahar S, Nin V, Barbosa MT, Chini EN \& Sassone-Corsi P 2011 Altered behavioral and metabolic circadian rhythms in mice with disrupted $\mathrm{NAD}^{+}$oscillation. Aging 3 794-802.

Salgado-Delgado R, Angeles-Castellanos M, Saderi N, Buijs RM \& Escobar C 2010 Food intake during the normal activity phase prevents obesity and circadian desynchrony in a rat model of night work. Endocrinology 151 1019-1029. (doi:10.1210/en.2009-0864)

Salgado-Delgado RC, Saderi N, Basualdo Mdel C, Guerrero-Vargas NN, Escobar C \& Buijs RM 2013 Shift work or food intake during the rest phase promotes metabolic disruption and desynchrony of liver genes in male rats. PLoS ONE 8 e60052. (doi:10.1371/journal.pone.0060052)

Scarpulla RC 2008 Transcriptional paradigms in mammalian mitochondrial biogenesis and function. Physiological Reviews 88 611-638. (doi:10.1152/physrev.00025.2007)

Scheer FA \& Shea SA 2014 Human circadian system causes morning peak in pro-thrombotic plasminogen activator inhibitor-1 (PAI-1) independent of sleep/wake cycle. Blood 123 590-593. (doi:10.1182/blood-2013-07517060)

Scheer FA, Ter Horst GJ, van Der Vliet J \& Buijs RM 2001 Physiological and anatomic evidence for regulation of the heart by suprachiasmatic nucleus in rats. American Journal of Physiology. Heart and Circulatory Physiology 280 H1391-H1399.

Scheer FA, Hilton MF, Mantzoros CS \& Shea SA 2009 Adverse metabolic and cardiovascular consequences of circadian misalignment. PNAS 106 4453-4458. (doi:10.1073/pnas.0808180106)

Scheer FA, Hu K, Evoniuk H, Kelly EE, Malhotra A, Hilton MF \& Shea SA 2010 Impact of the human circadian system, exercise, and their interaction on cardiovascular function. PNAS 107 20541-20546. (doi:10.1073/pnas.1006749107)

Scheer FA, Michelson AD, Frelinger AL III, Evoniuk H, Kelly EE, McCarthy M, Doamekpor LA, Barnard MR \& Shea SA 2011 The human endogenous circadian system causes greatest platelet activation during the biological morning independent of behaviors. PLOS ONE 6 e24549. (doi:10.1371/journal.pone.0024549)

Schlierf G \& Dorow E 1973 Diurnal patterns of triglycerides, free fatty acids, blood sugar, and insulin during carbohydrate-induction in man and their modification by nocturnal suppression of lipolysis. Journal of Clinical Investigation 52 732-740. (doi:10.1172/JCI107235)

Schmid SM, Hallschmid M, Jauch-Chara K, Bandorf N, Born J \& Schultes B 2007 Sleep loss alters basal metabolic hormone secretion and modulates the dynamic counterregulatory response to hypoglycemia. Journal of Clinical Endocrinology and Metabolism 92 3044-3051. (doi:10.1210/jc.2006-2788)

Schmid SM, Jauch-Chara K, Hallschmid M \& Schultes B 2009 Mild sleep restriction acutely reduces plasma glucagon levels in healthy men. Journal of Clinical Endocrinology and Metabolism 94 5169-5173. (doi:10.1210/jc.2009-0969)

Shang Z, Lu C, Chen S, Hua L \& Qian R 2012 Effect of H(2)S on the circadian rhythm of mouse hepatocytes. Lipids in Health and Disease 1123. (doi:10.1186/1476-511X-11-23)

Shea SA, Hilton MF, Hu K \& Scheer FA 2011 Existence of an endogenous circadian blood pressure rhythm in humans that peaks in the evening. Circulation Research 108980-984. (doi:10.1161/CIRCRESAHA.110.233668)

Shi SQ, Ansari TS, McGuinness OP, Wasserman DH \& Johnson CH 2013 Circadian disruption leads to insulin resistance and obesity. Current Biology 23 372-381. (doi:10.1016/j.cub.2013.01.048)

Shostak A, Meyer-Kovac J \& Oster H 2013 Circadian regulation of lipid mobilization in white adipose tissues. Diabetes 62 2195-2203. (doi:10.2337/db12-1449)

Sladek M, Rybova M, Jindrakova Z, Zemanova Z, Polidarova L, Mrnka L, O'Neill J, Pacha J \& Sumova A 2007 Insight into the circadian clock within rat colonic epithelial cells. Gastroenterology 133 1240-1249. (doi:10.1053/j.gastro.2007.05.053) 
Sollberger A 1964 The control of circadian glycogen rhythms. Annals of the New York Academy of Sciences 117 519-554. (doi:10.1111/j.1749-6632. 1964.tb48204.x)

Sonoda J, Mehl IR, Chong LW, Nofsinger RR \& Evans RM 2007 PGC-1ß controls mitochondrial metabolism to modulate circadian activity, adaptive thermogenesis, and hepatic steatosis. PNAS 104 5223-5228. (doi:10.1073/pnas.0611623104)

Sookoian S, Gemma C, Fernandez Gianotti T, Burgueno A, Alvarez A, Gonzalez CD \& Pirola CJ 2007 Effects of rotating shift work on biomarkers of metabolic syndrome and inflammation. Journal of Internal Medicine 261 285-292. (doi:10.1111/j.1365-2796.2007.01766.x)

Stavinoha MA, Rayspellicy JW, Hart-Sailors ML, Mersmann HJ, Bray MS \& Young ME 2004 Diurnal variations in the responsiveness of cardiac and skeletal muscle to fatty acids. American Journal of Physiology. Endocrinology and Metabolism 287 E878-E887. (doi:10.1152/ajpendo.00189.2004)

Storch KF, Lipan O, Leykin I, Viswanathan N, Davis FC, Wong WH \& Weitz CJ 2002 Extensive and divergent circadian gene expression in liver and heart. Nature 417 78-83. (doi:10.1038/nature744)

Stunkard AJ \& Allison KC 2003 Two forms of disordered eating in obesity: binge eating and night eating. International Journal of Obesity and Related Metabolic Disorders 27 1-12. (doi:10.1038/sj.ijo.0802186)

Summa KC, Voigt RM, Forsyth CB, Shaikh M, Cavanaugh K, Tang Y, Vitaterna MH, Song S, Turek FW \& Keshavarzian A 2013 Disruption of the circadian clock in mice increases intestinal permeability and promotes alcohol-induced hepatic pathology and inflammation. PLoS ONE 8 e67102. (doi:10.1371/journal.pone.0067102)

Swanson G, Forsyth CB, Tang Y, Shaikh M, Zhang L, Turek FW \& Keshavarzian A 2011 Role of intestinal circadian genes in alcoholinduced gut leakiness. Alcoholism, Clinical and Experimental Research $\mathbf{3 5}$ 1305-1314. (doi:10.1111/j.1530-0277.2011.01466.x)

Takahashi JS, Hong HK, Ko CH \& McDearmon EL 2008 The genetics of mammalian circadian order and disorder: implications for physiology and disease. Nature Reviews. Genetics 9 764-775. (doi:10.1038/nrg2430)

Tasaka Y, Inoue S, Maruno K \& Hirata Y 1980 Twenty-four-hour variations of plasma pancreatic polypeptide, insulin and glucagon in normal human subjects. Endocrinologia Japonica 27 495-498. (doi:10.1507/ endocrj1954.27.495)

Tsai JY, Kienesberger PC, Pulinilkunnil T, Sailors MH, Durgan DJ, VillegasMontoya C, Jahoor A, Gonzalez R, Garvey ME, Boland B et al. 2010 Direct regulation of myocardial triglyceride metabolism by the cardiomyocyte circadian clock. Journal of Biological Chemistry $\mathbf{2 8 5}$ 2918-2929. (doi:10.1074/jbc.M109.077800)

Tsai JY, Villegas-Montoya C, Boland BB, Blasier Z, Egbejimi O, Gonzalez R, Kueht M, McElfresh TA, Brewer RA, Chandler MP et al. 2013 Influence of dark phase restricted high fat feeding on myocardial adaptation in mice. Journal of Molecular and Cellular Cardiology 55 147-155. (doi:10. 1016/j.yjmcc.2012.09.010)

Um JH, Yang S, Yamazaki S, Kang H, Viollet B, Foretz M \& Chung JH 2007 Activation of $5^{\prime}$-AMP-activated kinase with diabetes drug metformin induces casein kinase $\mathrm{I} \varepsilon(\mathrm{CKI} \varepsilon)$-dependent degradation of clock protein mPer2. Journal of Biological Chemistry 282 20794-20798. (doi:10.1074/ jbc.C700070200)

Van Cauter E \& Copinschi G 1999 Interactions between growth hormone secretion and sleep. In Human Growth Hormone Secretion: Basic and Clinical Research, pp 261-284. Eds RG Smith \& MO Turner. Totowa, NJ, USA: Humana Press, Inc.

Van Cauter E \& Spiegel K 1999 Circadian and sleep control of endocrine secretions. In Neurobiology of Sleep and Circadian Rhythms, pp 397-426, Ch 133. Eds FW Turek \& PC Zee. New York, NY, USA: Marcel Dekker.

Van Cauter E, Blackman JD, Roland D, Spire JP, Refetoff S \& Polonsky KS 1991 Modulation of glucose regulation and insulin secretion by circadian rhythmicity and sleep. Journal of Clinical Investigation $\mathbf{8 8}$ 934-942. (doi:10.1172/JCI115396)

Vinje S, Stroes E, Nieuwdorp M \& Hazen SL 2014 The gut microbiome as novel cardio-metabolic target: the time has come!. European Heart Journal 35 883-887. (doi:10.1093/eurheartj/eht467)

Voet D \& Voet JG 2004 In Biochemistry. New York, NY, USA: Wiley.

Whichelow MJ, Sturge RA, Keen H, Jarrett RJ, Stimmler L \& Grainger S 1974 Diurnal variation in response to intravenous glucose. BMJ 1 488-491. (doi:10.1136/bmj.1.5906.488)

Woerle HJ, Meyer C, Dostou JM, Gosmanov NR, Islam N, Popa E, Wittlin SD, Welle SL \& Gerich JE 2003 Pathways for glucose disposal after meal ingestion in humans. American Journal of Physiology. Endocrinology and Metabolism 284 E716-E725. (doi:10.1152/ajpendo.00365.2002)

Woldt E, Sebti Y, Solt LA, Duhem C, Lancel S, Eeckhoute J, Hesselink MK, Paquet C, Delhaye S, Shin Y et al. 2013 Rev-erb- $\alpha$ modulates skeletal muscle oxidative capacity by regulating mitochondrial biogenesis and autophagy. Nature Medicine 19 1039-1046. (doi:10.1038/nm.3213)

Wu N, Yin L, Hanniman EA, Joshi S \& Lazar MA 2009 Negative feedback maintenance of heme homeostasis by its receptor, Rev-erb $\alpha$. Genes and Development 23 2201-2209. (doi:10.1101/gad.1825809)

Wurtman RJ, Rose CM, Chou C \& Larin FF 1968 Daily rhythms in the concentrations of various amino acids in human plasma. New England Journal of Medicine 279 171-175. (doi:10.1056/ NEJM196807252790401)

Yang JN, Wang Y, Garcia-Roves PM, Bjornholm M \& Fredholm BB 2010 Adenosine A(3) receptors regulate heart rate, motor activity and body temperature. Acta Physiologica 199 221-230. (doi:10.1111/j.1748-1716. 2010.02091.x)

Yin L \& Lazar MA 2005 The orphan nuclear receptor Rev-erb $\alpha$ recruits the N-CoR/histone deacetylase 3 corepressor to regulate the circadian Bmal1 gene. Molecular Endocrinology 19 1452-1459. (doi:10.1210/ me.2005-0057)

Yoo SH, Mohawk JA, Siepka SM, Shan Y, Huh SK, Hong HK, Kornblum I, Kumar V, Koike N, Xu M et al. 2013 Competing E3 ubiquitin ligases govern circadian periodicity by degradation of CRY in nucleus and cytoplasm. Cell 152 1091-1105. (doi:10.1016/j.cell.2013.01.055)

Yoshii K, Ishijima S \& Sagami I 2013 Effects of NAD(P)H and its derivatives on the DNA-binding activity of NPAS2, a mammalian circadian transcription factor. Biochemical and Biophysical Research Communications 437 386-391. (doi:10.1016/j.bbrc.2013.06.086)

Young ME, Razeghi P, Cedars AM, Guthrie PH \& Taegtmeyer H 2001 Intrinsic diurnal variations in cardiac metabolism and contractile function. Circulation Research 89 1199-1208. (doi:10.1161/hh2401.100741)

Young ME, Wilson CR, Razeghi P, Guthrie PH \& Taegtmeyer H 2002 Alterations of the circadian clock in the heart by streptozotocininduced diabetes. Journal of Molecular and Cellular Cardiology 34 223-231. (doi:10.1006/jmcc.2001.1504)

Zhang EE, Liu Y, Dentin R, Pongsawakul PY, Liu AC, Hirota T, Nusinow DA, Sun X, Landais S, Kodama Y et al. 2010 Cryptochrome mediates circadian regulation of cAMP signaling and hepatic gluconeogenesis. Nature Medicine 16 1152-1156. (doi:10.1038/nm.2214)

Zhou P, Ross RA, Pywell CM, Liangpunsakul S \& Duffield GE 2014 Disturbances in the murine hepatic circadian clock in alcohol-induced hepatic steatosis. Scientific Reports 4 3725. (doi:10.1038/srep03725)

Zizi F, Jean-Louis G, Brown CD, Ogedegbe G, Boutin-Foster C \& McFarlane SI 2010 Sleep duration and the risk of diabetes mellitus: epidemiologic evidence and pathophysiologic insights. Current Diabetes Reports 10 43-47. (doi:10.1007/s11892-009-0082-x)

Zylka M, Shearman L, Weaver D \& Reppert S 1998 Three period homologs in mammals: differential light responses in the suprachiasmatic circadian clock and oscillating transcripts outside of brain. Neuron 20 1103-1110. (doi:10.1016/S0896-6273(00)80492-4)

Received in final form 5 June 2014

Accepted 12 June 2014

Accepted Preprint published online 13 June 2014 http://joe.endocrinology-journals.org DOI: $10.1530 / \mathrm{JOE}-14-0200$
(C) 2014 Society for Endocrinology Printed in Great Britain 